CDD: 160

\title{
FORMAL SEMANTICS FOR PROPOSITIONAL ATTITUDES
}

\author{
DANIEL VANDERVEKEN \\ Université du Québec, \\ Trois-Rivières \\ CANADA \\ daniel.vanderveken@uqtr.ca
}

\begin{abstract}
Contemporary logic is confined to a few paradigmatic attitudes such as belief, knowledge, desire and intention. My purpose is to present a general modeltheoretical semantics of propositional attitudes of any cognitive or volitive mode. In my view, one can recursively define the set of all psychological modes of attitudes. As Descartes anticipated, the two primitive modes are those of belief and desire. Complex modes are obtained by adding to primitive modes special cognitive and volitive ways or special propositional content or preparatory conditions. According to standard logic of attitudes (Hintikka), human agents are either perfectly rational or totally irrational. I will proceed to a finer analysis of propositional attitudes that accounts for our imperfect but minimal rationality. For that purpose I will use a non standard predicative logic according to which propositions with the same truth conditions can have different cognitive values and I will explicate subjective in addition to objective possibilities. Next I will enumerate valid laws of my general logic of propositional attitudes. At the end I will state principles according to which minimally rational agents dynamically revise attitudes of any mode.
\end{abstract}

Keywords: Philosophical logic. Propositional attitudes. Psychological modes. Minimal rationality.

\section{ANALYSIS OF PROPOSITIONAL ATTITUDES}

Let me first explain my componential analysis of psychological modes and the principles of my logic of propositional attitudes. (For more explanations see my paper Vanderveken (2008)). By nature attitudes, which are directed at objects and facts of the world, have logically related conditions of possession and of satisfaction. Whoever 
possesses an attitude is in principle able to determine what has to happen in the world in order that his or her attitude is satisfied. Beliefs are satisfied whenever they are true, desires whenever they are realized and intentions whenever they are executed. Propositional attitudes consist of a psychological mode $M$ with a propositional content $P$. They are the simplest kinds of individual attitudes directed at facts. Many philosophers tend to reduce all propositional attitudes to sums of beliefs and desires. However, our intentions are much more than a desire to do something with a belief that we are able to do it. Of course, all cognitive attitudes (e.g. conviction, faith, confidence, knowledge, certainty, presumption, pride, arrogance, surprise, amazement, stupefaction, prevision, anticipation and expectation) are beliefs and all volitive attitudes (e.g. wish, will, intention, ambition, project, hope, aspiration, satisfaction, pleasure, enjoyment, delight, gladness, joy, elation, amusement, fear, regret, sadness, sorrow, grief, remorse, terror) are desires. But psychological modes divide into other components than the basic categories of cognition and volition. In my view, complex modes have a proper way of believing or desiring, proper conditions on their propositional content or proper preparatory conditions. We feel our beliefs and desires in a lot of ways. Many modes require a special cognitive or volitive way of believing or desiring. Thus, knowledge is a belief based on strong evidence that gives confidence and guarantees truth. Whoever has an intention feels such a strong desire that he or she is disposed to act in order to satisfy that desire. From a logical point of view, a cognitive or volitive way is a function $f_{\bar{\omega}}$ which restricts basic psychological categories. Like illocutionary forces, modes also have propositional content and preparatory conditions. Previsions and anticipations are directed towards the future. Intentions are desires to carry out a present or future action. From a logical point of view, a condition on the propositional content is a function $f_{\theta}$ that associates which each agent and moment a set of propositions. Any agent of an 
attitude or of an illocution presupposes certain propositions. His or her attitude and illocution would be defective if these propositions were then false. Thus promises and intentions have the preparatory condition that the agent is then able to do the action represented by their propositional content. No agent can lie to himself. Whoever has an attitude both believes and presupposes that its preparatory conditions are fulfilled. A preparatory condition is a function $f_{\Sigma}$ associating with each agent, moment and propositional content a set of propositions that the agent would presuppose and believe if he had then an attitude with that preparatory condition and propositional content. The sets of cognitive and volitive ways, of propositional content and of preparatory conditions are Boolean algebras. They contain a neutral mode, preparatory or propositional condition and they are closed under the operations of union and intersection.

On the basis of my analysis, one can formally distinguish different modes of attitudes like fear, regret and sadness which apparently reduce to the same sums of beliefs and desires. Identical psychological modes have the same components. Possession conditions of propositional attitudes are entirely determined by components of their mode. By definition, an agent a possesses a cognitive (or volitive) attitude of the form $M(P)$ at a moment $m$ when he or she then believes (or desires) the propositional content $P$, he or she feels that belief or desire that $P$ in the cognitive or volitive way $\bar{\omega}_{M}$ proper to psychological mode $M$, the proposition $P$ then satisfies propositional content conditions $\Theta_{M}(a, m)$ and finally that agent then presupposes and believes all propositions determined by preparatory conditions $\Sigma_{M}(a, m, P)$ of mode $M$ with respect to the content $P$. Thus an agent intends that $P$ at a moment when proposition $P$ then represents a present or future action of that agent, he or she desires so much that action that he or she is committed to carrying it out and moreover that agent then presupposes and believes to be able to carry it out. An attitude strongly commits an 
agent to another at a moment when he or she could not then have that attitude without having the second. Thus whoever believes that it will rain tomorrow then foresees rain tomorrow. Some attitudes strongly commit the agent to another at particular moments. Whoever believes now that it will rain tomorrow foresees rain tomorrow. The day after tomorrow the same belief won't be a prevision. It will be a belief about the past. An attitude contains another when it strongly commits any agent to that other attitude at any moment. There are strong and weak psychological commitments just as there are strong and weak illocutionary commitments (See Searle and Vanderveken (1985)). One must distinguish between the overt possession of an attitude and a simple psychological commitment to that attitude. Whoever believes that every man is mortal is weakly committed to believing that Nebuchadnezzar is mortal, even if he has not Nebuchadnezzar's concept in mind and if he or she does not then possess the second belief. No one could simultaneously believe the first universal proposition and the negation of the second.

Psychological modes are not a simple sequence of a basic psychological category, a cognitive or volitive way, a propositional content condition and a preparatory condition. For their components are not logically independent. Certain components determine others of the same or of another kind. Thus the volitive way of the mode of intention determines the propositional content condition that it represents a present or future action of the agent and the preparatory condition that that agent is then able to carry out that action. The two primitive modes of belief and desire are the simplest cognitive and volitive modes. They have no special cognitive or volitive way, no special propositional content or preparatory condition. Complex modes are obtained by adding to primitive modes special cognitive or volitive ways, propositional content conditions or preparatory conditions. Thus the mode of prevision $M_{\text {foresee }}$ is obtained by adding to the mode of belief the 
propositional content condition $\Theta_{\text {future }}$ that associates with each agent and moment the set of propositions that are future with respect to that moment. $M_{\text {foresee }}=\left[\Theta_{\text {future }}\right]$ Belief. The mode of expectation is obtained from that of prevision by adding the special cognitive way that the agent is then in a state of expectation. $M_{\text {expect }}=\left[\bar{\omega}_{\text {expecation }}\right] M_{\text {foresee }}$. The mode of hope is obtained from that of desire by adding the special cognitive way that the agent is then uncertain as regards the existence and the inexistence of the represented fact and the preparatory condition that that fact is then possible. The mode of satisfaction is obtained from that of desire by adding the preparatory condition that the desired fact exists. The mode of pleasure has, in addition, the volitive way that the satisfaction of the desire puts the agent in a state of pleasure and the preparatory condition that it is good for the agent. Because all operations on modes add new components, they generate stronger modes. Attitudes $M(P)$ with a complex mode contains attitudes $M^{\prime}(P)$ whose modes have less components. A lexical analysis of terms for attitudes based on my componential analysis explains which name stronger psychological modes. One can show comparative strength by drawing tableaux. See the appendix.

From a logical point of view, propositional attitudes are not pairs of a mode and a propositional content. Whoever possesses a propositional attitude of the form $M(P)$ applies the mode $M$ to the content $P$ so as to determine under which conditions it is satisfied. Identical propositional attitudes can have a different psychological mode. What matters is that their propositional content is the same and that whoever possesses one attitude also possesses the other. Attitudes with the same content and possession conditions fulfill the same function in psychological life. Thus the belief that it will always be the case that $2+2=4$ is also a prevision.

Propositions with the same truth conditions are not the contents of the same attitudes. Moreover agents ignore the necessary truth of 
many propositions that they understand. They have to learn a lot of essential properties of objects. By essential property of an object I mean a property that it really possesses in any possible circumstance. An essential property of each agent is to have certain parents. Some do not know their parents. Others are wrong about their identity. According to standard logic of attitudes (cf. Hintikka (1971)), relations of psychological compatibility with the truth of beliefs and the realization of desires are modal relations of accessibility between agents and moments, on one hand, and possible circumstances, on the other hand. Possible circumstances are compatible with agents' beliefs at each moment of time. To each agent $a$ and moment $m$ there corresponds a unique set Belief $(a, m)$ of possible circumstances that are compatible with the truth of all beliefs of that agent at that moment. In Hintikka's logic, an agent believes a proposition at a moment when that proposition is true in all possible circumstances that are compatible with what that agent then believes. Given this approach, human agents are logically omniscient. They believe necessarily true propositions and their beliefs are closed under strict implication. Moreover, they are either perfectly rational or totally irrational. Agents are perfectly rational when at least one circumstance is compatible with what they believe. Otherwise, they are totally irrational. Whoever believes a necessary falsehood believes everything.

In my approach, all circumstances remain possible. So objects keep their essential properties (each of us keeps his real parents) and necessarily true propositions remain true in all circumstances. In order to account for our human inconsistency and minimal rationality, I advocate a predicative non classical propositional logic which takes into account acts of predication and reference that we make in apprehending propositions.

In my view, each proposition has a finite structure of constituents. It predicates attributes (properties or relations) of objects subsu- 
med under concepts. We understand a proposition when we understand which attributes our objects of reference must possess in a possible circumstance in order that this proposition be true in that circumstance.

We understand most propositions without knowing in which circumstances they are true, because we ignore real denotations of their attributes and concepts in many circumstances. One can refer to a colleague's mother without knowing who she is. However we can in principle think of persons who could be that mother. So in any possible use of language, there are a lot of possible denotation assignments to attributes and concepts in addition to the standard real denotation assignment which associates with each propositional constituent its actual denotation in every possible circumstance. They are functions of the same type that associate with each individual concept a unique individual or no individual at all in every possible circumstance. According to the real denotation assignment, my colleague's mother is the woman who gave birth to him. According to other possible denotation assignments, his mother is another person. However, all possible denotation assignments respect meaning postulates. According to any, a mother is a female parent. We ignore the real denotation of most concepts and attributes in many circumstances. But we can think of denotations that they could have. When we have in mind concepts and attributes only some possible denotation assignments to them are then compatible with our beliefs. Suppose that according to you my mother is Belgian. In that case, possible denotation assignments according to which she is not Belgian are incompatible with your beliefs. Possible denotation assignments rather than possible circumstances are compatible with agents' beliefs. So logic can account for subjective possibilities. Because my truth definition is relative to both circumstances and denotation assignments, most propositions have a lot of possible truth conditions. Of course, in order to be true in a circumstance propositions have to be true in that 
circumstance according to the real denotation assignment. So among all possible truth conditions of a proposition, its real Carnapian truth conditions determine the set of possible circumstances where it is true according to the real denotation assignment.

In my view, identical propositions make the same predications and they are true in the same circumstances according to the same possible denotation assignments. Necessarily true propositions with a different structure of constituents are therefore different. So are propositions that are not true according to the same possible denotation assignments to their constituents. We do not understand them to be true in the same possible circumstances. Few necessarily true propositions are pure tautologies that we know a priori. A proposition is necessarily true when it is true in every possible circumstance according to the real denotation assignment. In order to be tautologically true, a proposition has to be true in every circumstance according to every possible denotation assignment. Unlike the proposition that my mother is a mother, the necessarily true proposition that my mother is Gabrielle Louise Albertine Charron is not a pure tautology. It is false according to possible denotation assignments. A proposition is subjectively possible when it is true in a circumstance according to a denotation assignment. In order to be objectively possible it must be true in a circumstance according to the real denotation assignment. The logic of attitudes requires a ramified conception of time compatible with indeterminism. Agents live and persist in an indeterminist world. First of all their attitudes and illocutions are not determined. They could have thought or spoken differently. Secondly, their future is open. In branching time, a moment is a complete possible state of the actual world at a certain instant and the temporal relation of anteriority between moments is partial. There is a single causal route to the past. However, there are multiple future routes. Consequently, the set of moments of time is a tree-like frame: 


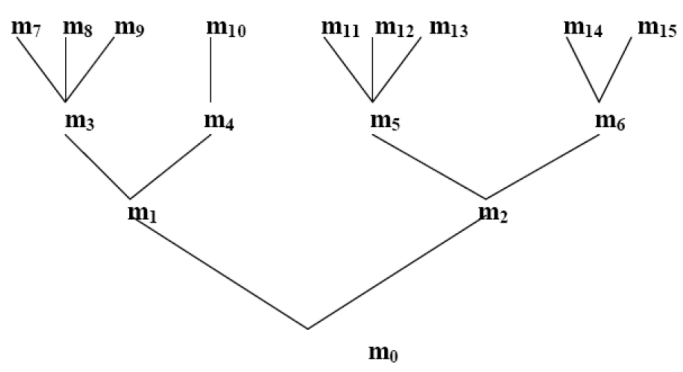

A maximal chain $h$ of moments of time is called a history. It represents a possible course of history of our world. As Belnap, Perloff and $\mathrm{Xu}$ (2001) pointed out, each possible circumstance is a pair of a moment $m$ and of a history $h$ to which that moment belongs. Thanks to histories temporal logic can analyze important modal notions like settled truth and historic necessity. Certain propositions are true at a moment according to all histories. Their truth is then settled at that moment no matter how the world continues. So are propositions which attribute attitudes to agents. Whoever desires something at a moment then desires that thing no matter what happens later. Contrary to the past, the future is open. The world can continue in various ways after indeterminist moments. Thus the truth of future propositions is not settled at such moments. It depends on which historical continuation of that moment is under consideration. When a moment can continue in different possible ways, its actual future continuation is not then determined. However, as Occam (see Prior (1967)) pointed out, if the world continues after a moment, it will continue in one way. The actual historic continuation of any moment is unique even if it is still undetermined at that moment. Indeterminism cannot prevent that unicity. So each moment $m$ has a proper history $h_{m}$ in each model. A proposition is true at a moment $m$ according to a denotation assignment when it is true according to that assignment at that moment in its proper history $h_{m}$. Coinstantaneous moments which belong to the same instant are 
on the same horizontal line in each tree-like frame. Logic analyzes historic necessity by quantifying over coinstantaneous moments. ${ }^{1}$

Like elementary illocutions propositional attitudes are directed towards facts of the world represented by their propositional content. Most often agents establish a correspondence between their ideas and things to which they refer. According to them their ideas correspond to represented things in the world or represented things have to correspond to their ideas. Their attitudes and illocutions have for that reason satisfaction conditions. At each moment where agents think and act they ignore how the world will continue. However, their attitudes and actions are directed toward the real historic continuation of that moment. In order that a present desire directed at the future is realized, it is not enough that things will be at a posterior moment as the agent now desires. They must be so later in the real future. So the satisfaction of propositional attitudes and elementary illocutions of an agent at an indeterminist moment requires the truth of their propositional content at that moment in its real historic continuation. The notion of satisfaction is a generalization of the notion of actual truth that covers attitudes and elementary illocutions with a non empty direction of fit. Just as a belief at a moment is satisfied when it is then true, a wish and a desire are satisfied when they are then realized; a prevision, an expectation, a hope and an aspiration when they are fulfilled; an intention, a project and a plan when they are then executed; a fear and a fright when the feared thing does not then happen.

Like assertive illocutions, cognitive attitudes have the mind-to-things direction of fit. They are satisfied when their propositional content is true at the moment under consideration. The agent's ideas correspond to things as they are then in the world. In the cognitive case, when the

\footnotetext{
${ }^{1}$ The proposition that $P$ is then necessary (in symbols $\square P$ ) is true at a moment when $P$ is true at all coinstantaneous moments according to all histories.
} 
agent realizes that there is no correspondence, he immediately changes his beliefs. This is why satisfaction amounts to truth in the case of cognitive attitudes. However, this is not the case for volitive attitudes whose direction of fit goes from things to ideas. For the world and not the agent is at fault in the case of dissatisfaction of volitive attitudes. The agent can keep his desires and remains dissatisfied. Most often agents having a volitive attitude desire the fact represented by the propositional content no matter how that fact turns to be existent in the world. So most volitive attitudes are satisfied when their content is then true, no matter for which reason. Things are then such as the agent desires them to be, no matter what is the cause of their existence. However volitive attitudes like will, intentions, pretensions and ambitions have a special volitive way which requires that things fit the agent's ideas because he or she wants them in that way. Such wanting attitudes as well as illocutions like orders, commands, pledges and promises that express the speaker's will have self-referential satisfaction conditions. Their satisfaction requires more than the actual truth of their propositional content. It requires that the represented fact turns to be existent in order to satisfy the agent's attitude. In order to execute a prior intention, an agent must later carry out the intended action because of that previous intention. If the agent is later obliged to act, he or she does not then execute the prior intention. My logic of attitudes explains such cases of self-referential satisfaction by relying on the notion of intentional causation. The agent's attitude must then be a practical reason why the represented fact turns to be existent.

Volitive modes like joy, gladness, pride, pleasure regret, sadness, sorrow, and shame have the empty direction of fit. Agents of such attitudes do not want to establish a correspondence between their ideas and things in the world. They just take for granted either correspondence or lack of correspondence. In the case of joy, gladness, pride and pleasure, the agent believes that the desired fact exists. In the case of 
regret, sorrow and shame, he believes the contrary. The first attitudes have the preparatory condition that their propositional content is then true, the second attitudes have the opposite preparatory condition that their content is then false. Volitive attitudes with such special preparatory condition have the empty direction of fit and no proper satisfaction conditions. Instead of being satisfied or dissatisfied, they are just appropriate or inappropriate.

\subsection{My new explication of the basic categories of cognition and volition}

In my approach, attitudes of agents are about objects that they represent under concepts. No agent can have a propositional attitude without having in mind consciously or potentially all attributes and concepts of its content. Whoever has a conscious propositional attitude has in mind consciously its attributes and concepts. Whoever has an unconscious attitude can in principle express these senses thanks to his language. Otherwise, he would be unable to determine under which conditions his attitude is satisfied. Secondly, possible denotation assignments to propositional constituents rather than possible circumstances are compatible with the satisfaction of agents' attitudes. So there corresponds to each agent $a$ and moment $m$ a unique set Belief $(a, m)$ of possible denotation assignments to attributes and concepts that are compatible with the truth of beliefs of that agent at that moment. Belief $(a, m)$ is the set $V a l$ of all possible denotation assignments when agent $a$ has no attribute or concept in mind at moment $m$. That agent has then no attitudes. Otherwise, Belief $(a, m)$ is a non empty proper subset of $V a l$. Any agent who has in mind propositional constituents respects meaning postulates governing them in determining truth conditions of propositions. Otherwise he could not express them. Because meaning postulates are entirely determined by meaning, agents necessarily internalize such postulates in learning their language. 
Consequently there always are possible denotation assignments compatible with what an agent believes. In my view, an agent a believes a proposition at a moment $m$ when he has then in mind all its concepts and attributes and that proposition is true at that moment according to all possible denotation assignments belonging to Belief $(a, m)$. We all now have beliefs directed at the future. Such beliefs are true when things will be as we believe in the real future continuation of the present moment.

Similarly, to each agent $a$ and moment $m$ there corresponds a unique non empty set Desire $(a, m)$ of possible denotation assignments to attributes and concepts that are compatible with the realization of all desires of that agent at that moment. There is however the following important difference between desire and belief. We often believe, but we cannot desire, that objects are so and so without believing that they could be otherwise. For any desire contains a preference. Whoever feels a desire distinguishes two different ways in which represented objects could be in the actual world. In a first preferred way, objects are in the world as the agent desires, in a second way, they are not. The agent's desire is realized in the first case, it is unrealized in the second case. In order that an agent $a$ desires the fact represented by a proposition at a moment $m$, it is not enough that he has then in mind all its constituent senses and that the proposition is true at that moment according to all possible denotation assignments of Desire $(a, m)$. That proposition must moreover be false in at least one circumstance according to that agent.

My explication of belief and desire is compatible with philosophy of mind (See my paper Vanderveken (2009)). It distinguishes conscious and unconscious attitudes and accounts for the fact that human agents are not perfectly rational. We do not have in mind all concepts and attributes. So we ignore logical as well as necessary truths. Our knowledge is limited: we ignore which objects possess many properties in 
a lot of circumstances. In that case assignments associating different denotations to these properties in these circumstances are then compatible with our beliefs. We have false beliefs and unsatisfied desires. Possible denotation assignments compatible with our beliefs and desires need not assign real denotations to attributes that we have in mind. They can even violate essential properties of objects. In that case we have necessarily false beliefs and insatisfiable desires. My analysis solves traditional paradoxes. However human agents cannot be totally irrational. On the contrary, they are minimally rational. First of all, agents are paraconsistent in Newton da Costa's sense (see da Costa, Béziau and Bueno (2005)). They cannot believe or desire everything since some possible denotation assignments are always compatible with the satisfaction of their beliefs and desires. Moreover, their beliefs and desires commit them to others. For possible denotation assignments respect meaning postulates. Human agents are therefore minimally logically omniscient: they cannot have in mind what I called a pure tautology without knowing for certain that it is necessarily true. Represented objects could not be in another way according to them. Similarly, pure contradictions (negations of pure tautologies) are false in every possible circumstance according to any agent. We can neither believe nor desire contradictory things. Some hope that arithmetic is complete (a necessarily false proposition if Gödel's proof is right). But we could never believe nor desire both the completeness and the incompleteness of arithmetic (a pure contradiction). There is a new strong propositional implication much finer than Lewis' strict implication that is important for the analysis of psychological and illocutionary commitments. A proposition strongly implies another when whoever expresses that proposition is able to express the other and it cannot be true in a circumstance according to a possible denotation assignment unless the other proposition is also true in that circumstance according to that 
assignment. Strong implication is finite, tautological, paraconsistent, decidable and a priori known.

\section{THE IDEAL OBJECT LANGUAGE}

The ideal language $\mathscr{L}$ of my logic of propositional attitudes contains logical constants expressing material and formal universal features of psychological modes. Its formulas can express the logical form and determine felicity conditions of all kinds of propositional attitudes. Like natural languages, $\mathscr{L}$ contains indexical expressions whose sense is context-dependent.

The primitive types of $\mathscr{L}$ are: \#e,r,p, $\bar{\omega}, \theta, \Sigma$ and $M$. \#e is the type of concepts of individual objects, $r$ is the type of attributes of or relations between individuals, $p$ is the type of propositions; $\bar{\omega}$ is the type of ways of believing or desiring; $\theta$ the type of propositional content conditions; $\Sigma$ the type of preparatory conditions; and $M$ the type of psychological modes.

The vocabulary of $\mathscr{L}$ contains:

- individual constants of type $e$ expressing concepts of individual objects and agents; for each natural number $n$, predicates of degree $n$ expressing $n$-ary relations between individuals including the binary identity predicate $=_{2}$ and

- the logical constants: Bel, Des, $K_{\bar{\omega}}$, Want $t_{\bar{\omega}}$ and $I_{\bar{\omega}} t_{\bar{\omega}}$ that are of type $\bar{\omega}$, the constant $\operatorname{Int}_{\theta}$ of type $\theta$, the constant Truth $_{\Sigma}$ of type $\Sigma$ and a constant $1_{\zeta}$ for each type $\zeta \in\{\bar{\omega}, \theta, \Sigma\}$. Bel and Des name respectively the general categories of cognition and volition. Constants of type $\bar{\omega}$ name ways of believing and desiring. $K_{\bar{\omega}}$ names the special cognitive way of knowledge and $W$ ant $_{\bar{\omega}}$ and Int $_{\bar{\omega}}$ the special volitive ways of will and intention. Constants of type $\theta$ name propositional content conditions and constants of type $\Sigma$ preparatory conditions. In particular, Past ${ }_{\theta}$ names the condition that the propositional content 
is past and Future $_{\theta}$ that it is future. Int $t_{\theta}$ names the special propositional content condition of intentions. Truth $h_{\Sigma}$ names the preparatory condition that the propositional content is then true. $1_{\bar{\omega}}$ names the neutral way of having cognition and volition, $1_{\theta}$ the neutral propositional content condition and $1_{\Sigma}$ the neutral preparatory condition.

The syncategorematic symbols of $\mathscr{L}$ are: $\neg, \wedge, \cap, \cup,\}, \square, \diamond$, Was, Will, Settled, Actually, Tautological, $\rho,[,($,$] and )$.

\subsection{Rules of formation of $\mathscr{L}$}

\section{Terms for components of psychological modes}

(i) Constants of type $\bar{\omega}, \theta$ and $\Sigma$ are terms of $\mathscr{L}$ naming components of modes.

(ii) If $A$ and $B$ are component terms of $\mathrm{L}$ of the same type so are new terms $(A \cup B)$ and $(A \cap B)$. They name respectively the intersection and the union of components named by $A$ and $B$.

\section{Terms for psychological modes}

Expressions of the form $\left[A_{\bar{\omega}}, A_{\theta}, A_{\Sigma}, B e l\right]$ and $\left[A_{\bar{\omega}}, A_{\theta}, A_{\Sigma}, D e s\right]$ are terms of type $M$ of $\mathscr{L}$. The first term names the weakest cognitive mode and the second term the weakest volitive mode which have the way $A_{\bar{\omega}}$, the propositional content condition $A_{\theta}$ and the preparatory condition $A_{\Sigma}$.

\section{Propositional formulas}

(i) If $R_{n}$ is a predicate of degree $n$ and $t_{1}, \ldots, t_{n}$ is a sequence of $n$ individual constants, then $\left[R_{n} t_{1} \ldots t_{n}\right]$ is a propositional formula of $\mathscr{L}$ of type $p$ expressing the elementary proposition that predicates the attribute expressed by $R_{n}$ of the $n$ individuals under concepts expressed by $t_{1}, \ldots, t_{n}$ in that order.

(ii) If $A_{p}$ and $B_{p}$ are propositional formulas and $a$ an individual constant, $\neg A_{p}$, Settled $A_{p}, \square A p, W a s A_{p}$, Will $A_{p}$, Actually $A_{p}$, Tautological $\left.A_{p},\left(A_{p} \wedge B_{p}\right),\left(A_{p}\right\} B_{p}\right),\left[\right.$ Bela $\left.A_{\bar{\omega}} A_{p}\right], \diamond a A_{p},\left[\right.$ Desa $\left.A_{\bar{\omega}} A_{p}\right],\left[\rho A_{p} B_{p}\right]$, $\left(A_{\theta} a A_{p}\right),\left(A_{\Sigma} a A_{p}\right)$ and $\left[a>A_{p}\right]$ are new propositional formulas. 
$\neg A_{p}$ expresses the negation of proposition $A_{p}$. Will $A_{p}$ expresses the future proposition that it will be the case that $A_{p}$. Was $A_{p}$ expresses the past proposition that it has been the case that $A_{p}$. Settled $A_{p}$ expresses the modal proposition that it is settled that $A_{p} . \square A_{p}$ means that it is historically necessary that $A_{p}$, in the sense that it could not then have been otherwise than $A_{p}$. Actually $A_{p}$ expresses in each context the indexical proposition that it is then actual that $A_{p}$, that is to say that $A_{p}$ is true at the moment and in the history of that context ${ }^{2}$. Tautological $A_{p}$ means that proposition $A_{p}$ is a pure tautology. $\left(A_{p} \wedge\right.$ $B_{p}$ ) expresses the conjunction of the propositions expressed by $A_{p}$ and $B_{p}$ and $\left.\left(A_{p}\right\} B_{p}\right)$ means that proposition $A_{p}$ contains all elementary propositions of $B_{p}$. $\left.\left[\operatorname{Bela}_{\bar{\omega}} A_{p}\right)\right]$ and $\left.\left[\operatorname{Desa}_{\bar{\omega}} A_{p}\right)\right]$ respectively mean that agent a believes and desires that $A_{p}$ with the mode named by $A_{\bar{\omega}}$. $\diamond a A_{p}$ means that $A_{p}$ could then be true given all attitudes of agent $a$ 3. $\left[\rho A_{p} B_{p}\right]$ means that $A_{p}$ is true because of $B_{p}$.

$\left(A_{\theta} a A_{p}\right)$ means that proposition $A_{p}$ satisfies the propositional content condition $A_{\theta}$ as regards agent $a^{4} .\left(A_{\Sigma} a A_{p}\right)$ expresses in each context a proposition that is true in a circumstance $m / h$ when all the preparatory conditions $A_{\Sigma}$ are fulfilled as regards the agent $a$, the propositional content $A_{p}$ and the moment $m^{5}$. $\left[a>>A_{p}\right]$ means that agent $a$ presupposes $A_{p}$.

\footnotetext{
${ }^{2}$ The interpretation of the actuality connective makes a reference to the proper history of the moment of utterance.

${ }^{3} \diamond a A_{p}$ is true in circumstance $m / h$ when $A_{p}$ is true in a coinstantaneous circumstance where agent a has all attitudes that he or she has at moment $m$.

${ }^{4}$ Thus $\left(\operatorname{Int}_{\theta} a A_{p}\right)$ means that proposition $A_{p}$ represents a present or future action of agent $a$.

${ }^{5}$ If $I n t_{\Sigma}$ represents preparatory conditions of intention. ( $\left.I n t_{\Sigma} a A_{p}\right)$ means that agent is capable to carry out action $A_{p}$.
} 


\subsection{Rules of abbreviation}

I will use ordinary rules of abbreviation for the elimination of parentheses and type symbols and for the introduction of truth, modal and temporal connectives.

Historical possibility: $\diamond A={ }_{\operatorname{def}} \neg \square \neg A$

Universal Necessity: $\square A={ }_{\text {def }}$ Always $\square A$

Strong implication: $\left.\left(A_{p} \mapsto B_{p}\right)={ }_{\text {def }}\left(\square A_{p}\right\} B_{p}\right) \wedge$ Tautological $\left(A_{p} \rightarrow\right.$ $\left.B_{p}\right)$

Same structure of constituents: $\left.\left.\left.A_{p}\right\}\left\{B_{p}={ }_{\text {def }}\left(A_{p}\right\} B_{p}\right) \wedge\left(B_{p}\right\} A_{p}\right)\right)$

Propositional identity: $\left(A_{p}=B_{p}\right)={ }_{\text {def }}\left(A_{p} \mapsto B_{p}\right) \wedge\left(B_{p} \mapsto A_{p}\right)$

Identity of individual concepts: $(a=b)={ }_{\text {def }}\left[a={ }_{2} b\right]=\left[a={ }_{2} a\right]$

Identical attributes: $\left.R_{n}=R_{n}^{\prime}={ }_{\text {def }}\left[R_{n} t_{1} \ldots t_{n}\right]\right\}\left[R_{n}^{\prime} t_{1} \ldots t_{n}\right]$

Present $_{\theta} a A_{p}=$ def $_{\text {de }} \neg\left(\right.$ Past $_{\theta} a A_{p} \vee$ Future $\left._{\theta} a A_{p}\right)$

Falsehood $_{\Sigma} a A_{p}=_{\text {def }}$ Truth $_{\Sigma} a \neg A_{p}$

$\diamond_{\Sigma} a A_{p}=_{\text {def }}$ Truth $_{\Sigma} a \diamond A_{p}$ and $\neg \square_{\Sigma} a A_{p}={ }_{\text {def }}$ Truth $_{\Sigma} a \neg \square A_{p}$

The primitive mode of belief: Belief $=_{\text {def }}\left[1_{\bar{\omega}}, 1_{\theta}, 1_{\Sigma}, B e l\right]$

The primitive mode of desire: Desire $=_{\text {def }}\left[1_{\bar{\omega}}, 1_{\theta}, 1_{\Sigma}\right.$, Des $]$

The operation of imposing a cognitive or volitive way to a psychological mode: $\left[B_{\bar{\omega}}\right]\left[A_{\bar{\omega}}, A_{\theta}, A_{\Sigma}, \vartheta\right]={ }_{\text {def }}\left[\left(B_{\bar{\omega}} \cap A_{\bar{\omega}}\right), A_{\theta}, A_{\Sigma}, \vartheta\right]$ where $\vartheta$ is $B e l$ or Des.

The operation of adding a new propositional content condition to a psychological mode: $\left[B_{\theta}\right]\left[A_{\bar{\omega}}, A_{\theta}, A_{\Sigma}, \vartheta\right]={ }_{\text {def }}\left[A_{\bar{\omega}},\left(B_{\theta} \cap A_{\theta}\right), A_{\Sigma}, \vartheta\right]$

The operation of adding a new preparatory condition to a psychological mode: $\left[B_{\Sigma}\right]\left[A_{\bar{\omega}}, A_{\theta}, A_{\Sigma}, \vartheta\right]={ }_{\text {def }}\left[A_{\bar{\omega}}, A_{\theta},\left(B_{\Sigma} \cup A_{\Sigma}\right), \vartheta\right]$

The cognitive mode of knowledge: Knowledge $=_{\text {def }}\left[K_{\bar{\omega}}, 1_{\theta}\right.$, Truth $_{\Sigma}$, $\mathrm{Bel}]$

The volitive mode of will: Will $=_{\text {def }}\left[\left(\right.\right.$ Want $_{\bar{\omega}}$, Present ${ }_{\theta} \cup$ Future $_{\theta}$, $\left.\neg \square_{\Sigma} \cup \diamond_{\Sigma}, D e s\right]$

The volitive mode of intention: Intention $=_{\operatorname{def}}\left[\right.$ Int $\left._{\bar{\omega}}\right]\left[\right.$ Int $\left._{\theta}\right]$ Will The volitive mode of prior intention: Priorintention $=_{\text {def }}\left[\right.$ Future $\left._{\theta}\right]$ Intention 
Components of a psychological mode $A_{M}\left(A_{\varsigma}\right)={ }_{\text {def }}\left[A_{\varsigma}\right] A_{M}=A_{M}$ $A_{M}\left(A_{\varsigma}\right)$ means that $A_{\varsigma}$ is a component of mode $A_{M}$.

The null direction of fit: $\varnothing\left(A_{M}\right)={ }_{\text {def }} A_{M}($ Des $) \wedge\left(\left(A_{M}\left(\right.\right.\right.$ Truth $\left._{\Sigma}\right) \vee$ $\left(A_{M}\left(\right.\right.$ Falsehood $\left.\left._{\Sigma}\right)\right)$

Belief attribution: $\left[\right.$ Bela $\left.\left.A_{p}\right]={ }_{\operatorname{def}}\left[a B e l 1_{\bar{\omega}} A_{p}\right)\right]$

Desire attribution: Desa $\left.\left.A_{p}=\operatorname{def}_{[a D e s} 1_{\bar{\omega}} A_{p}\right)\right]$

$\left[\right.$ Bela $\left.A_{p}\right]$ expresses the proposition that agent a believes $A_{p}$ and $D e s a A_{p}$ that a desires $A_{p}$.

Conditions of possession of propositional attitudes

$\left[\operatorname{aHas}\left(\left[A_{\bar{\omega}}, A_{\theta}, A_{\Sigma}, \operatorname{Bel}\right] A_{p}\right)\right]==_{\operatorname{def}}\left(\left[\right.\right.$ Bela $\left.A_{\bar{\omega}} A_{p}\right] \wedge\left(A_{\theta} a A_{p}\right) \wedge\left[\right.$ Bela $A_{\Sigma} a$ $\left.A_{p}\right] \wedge\left[>>A_{\Sigma} a A_{p}\right]$

$\left[\operatorname{aHas}\left(\left[A_{\bar{\omega}}, A_{\theta}, A_{\Sigma}\right.\right.\right.$, Des $\left.\left.] A_{p}\right)\right]={ }_{\operatorname{def}}\left(\left[\right.\right.$ Desa $\left.A_{\bar{\omega}} A_{p}\right] \wedge\left(A_{\theta} a A_{p}\right) \wedge\left[\right.$ Bela $A_{\Sigma} a$ $\left.A_{p}\right] \wedge\left[>>a A_{\Sigma} a A_{p}\right] \wedge\left[\right.$ Bela $\neg$ Tautological $\left.\left.A_{p}\right]\right)$

$\left[\operatorname{aHas}\left(A_{M} A_{p}\right)\right]$ means that agent $a$ has the attitude with the mode $A_{M}$ and the content $A_{p}$.

Intention: aIntends $A_{p}=\operatorname{def}\left[\operatorname{aHas}\left(\operatorname{Intention} A_{p}\right)\right]$

Knowledge: $K a A_{p}={ }_{\text {def }}\left[\operatorname{aHas}\left(\right.\right.$ Knowledge $\left.\left.A_{p}\right)\right]$

Strong psychological commitment for an agent: $\left\{\left(A_{M} A_{p}\right),\left(B_{M} B_{p}\right)\right\}$ $a\left(C_{M} C_{p}\right)=_{\operatorname{def}} \square\left(\left(\left[\operatorname{aHas}\left(A_{M} A_{p}\right)\right] \wedge\left[\operatorname{aHas}\left(B_{M} B_{p}\right)\right]\right) \Rightarrow\left[\operatorname{aHas}\left(C_{M} C_{p}\right)\right]\right)$ Strong psychological commitment for all agents: $\left\{\left(A_{M} A_{p}\right),\left(B_{M} B_{p}\right)\right.$ $\left(C_{M} C_{p}\right)=_{\text {def }}$ Tautological $\left(A_{M} A_{p}\right),\left(B_{M} B_{p}\right) \vee a\left(C_{M} C_{p}\right)$

Psychological necessity $\square a A_{p}={ }_{\text {def }} \neg \diamond a \neg A_{p}$

Weak psychological commitment for an agent: $a \triangleright\left(A_{M} A_{p}\right)={ }_{d e f} \bowtie a \diamond a$ $\left[\operatorname{aHas}\left(A_{M} A_{p}\right)\right]$

$\left(A_{M} A_{p}\right) \triangleright a\left(B_{M} B_{p}\right)=_{\text {def }} \square\left(\left(\right.\right.$ aHas $\left.\left.A_{M} A_{p}\right) \Rightarrow a \triangleright\left(B_{\tau} B_{p}\right)\right)$

Weak psychological commitment for all: $\left(A_{M} A_{p}\right) \triangleright\left(B_{M} B_{p}\right)=_{\text {def }}$ Tautological $\left(A_{M} A_{p}\right) \triangleright a\left(B_{M} B_{p}\right)$

Identical attitudes $A_{M} A_{p}=B_{M} B_{p}=d_{\text {def }}\left(A_{p}=B_{p}\right) \wedge\left(A_{M} A_{p}\right.$ $\left.B_{M} B_{p}\right) \wedge\left(B_{M} B_{p} \triangleright A_{M} A_{p}\right)$

Satisfaction conditions of propositional attitudes:

Satisfied $\left(A_{M} a A_{p}\right)=_{\operatorname{def}}\left[\right.$ aHas $\left.\left.A_{M} A_{p}\right]\right] \wedge \neg \varnothing\left(A_{M}\right) \wedge$ Actually $A_{p} \wedge\left(A_{M}\right.$ 
$\left(\right.$ Want $\left._{\bar{\omega}}\right) \Rightarrow\left[\rho\left(\right.\right.$ Actually $\left._{p}\right)\left[\right.$ aHas $\left.\left.\left._{M} A_{p}\right]\right]\right)$. Satisfied $\left(A_{M} a A_{p}\right)$ means that the attitude of mode $A_{M}$ and propositional content $A_{p}$ of agent $a$ is (or will be) satisfied.

\section{THE STRUCTURE OF A SEMANTIC INTERPRETATION}

On the basis of previous philosophical considerations on the nature and felicity conditions of propositional attitudes, I have developed the following model-theoretical semantics in order to state valid laws of my logic. A standard possible interpretation or model for $\mathscr{L}$ is a structure $\mathcal{M}=<$ Time, Individuals, Agents, Concepts, Attributes, Val, Context, $\mathcal{U}$, Belief, Knowledge, Desire, Intention, Granted, Goal, Reason, \|\|$>$ where Time, Individuals, Agents, Concepts, Attributes, Val and Context are disjoint non-empty sets and Belief, Desire, Intention, Want, Reason, Val,U , Granted, Goal and \|\| are functions which satisfy the following meaning postulates.

(1) Time is a non-empty set of moments $m, m^{\prime}, m^{\prime \prime}, \ldots$ which represent complete possible states of the world at certain instants. There is a partial order $\leq$ on the set Time representing the temporal relation of anteriority or identity. When $m<m^{\prime}$, moment $m$ is in the past of moment $m^{\prime}$ and moment $m^{\prime}$ is in the future of possibilities of $m$. A moment is final when no moment is posterior to it. Because of indeterminism, the future can be open. But the past is unique. Thus there is historical connection and there is no backward branching. Consequently, the set Time of all moments of time is a tree-like frame. A maximal chain h of moments of Time is called a history. It represents a possible course of history of our world. Let History be the set of all histories. Among all histories to which belongs any non final moment there is one that will be the continuation of that moment. Any moment $m$ has then a proper history $h_{m}$ in each model. When $m$ is the last moment 
of a single history, that history is $h_{m}$. Since the proper history of any moment is unique, when moment $m$ continues, all moments $m^{\prime} \in h_{m}$ have the same real historic continuation: $h_{m^{\prime}}=h_{m}$. Two histories $h$ and $h^{\prime}$ are undivided at a moment $m$ when they have the same present and past at these moments. Alternative moments have the same past. Instant is a partition of the set Time that satisfies unique intersection and order preservation. Its members represent instants. Two moments of time $m$ and $m^{\prime}$ are coinstantaneous (in symbols: $m \oplus m^{\prime}$ ) when they belong to the same instant.

(2) Circumstance is the subset of the Cartesian product Time $\times$ History that contains all pairs of the form $m / h$ such that $m \in h$. Its elements are called possible circumstances. Circumstances are coinstantaneous when their moments are coinstantaneous.

(3) Individuals is a set of individual objects that contains a non empty subset Agents of agents. Individuals $s_{m}$ is the set of individuals existing at moment $m$ according to $\mathcal{M}$.

(4) Concepts is the set of individual concepts and Attributes is the set of attributes of individuals under concepts considered in model $\mathcal{M}$. For each number $n$, Attributes( $n$ ) is the subset of Attributes containing all relations of degree $n$. The set Attributes contains the binary relation of identity Identity and is closed under logical operations. See Bealer (1982) for operations on attributes.

(5) Context is an arbitrary non-empty set of possible contexts of utterance considered in model $\mathcal{M}$. Each context $c$ has distinctive features: a speaker $a_{c}$, a hearer $b_{c}$ who are agents $\left(a_{c}\right.$ and $b_{c} \in$ Agent) and a moment of utterance $m_{c} \in$ Time. By definition, the history $h_{c}$ of context $c$ is the historic continuation $h_{m}^{c}$ of its moment $m_{c}$ and the pair $m_{c} / h_{c}$ is the proper circumstance of that context. Any speaker exists at the moment of his utterance. Thus $a_{c} \in$ Individual $s_{m}^{c}$.

(6) The set $V a l$ is a proper subset of $(($ Concepts $\times$ Circumstances $)$ 
$\rightarrow($ Individuals $\cup\{\varnothing\})) \cup \bigcup_{n}(($ Attributes $(n) \times$ Circumstances $)$

$\rightarrow \mathcal{P}\left(\right.$ Concepts $\left.\left.^{n}\right)\right)$. Val contains all possible denotation assignments to propositional constituents of the model $\mathcal{M}$. For any individual concept $c_{e}$ and possible circumstance $m / h, \operatorname{val}\left(c_{e}, m / h\right) \in$ Individuals when individual concept $c_{e}$ has a denotation in the circumstance $m / h$ according to assignment val. Otherwise $\operatorname{val}\left(c_{e}, m / h\right)=\varnothing$. Because many attributes are intensional, attribute denotations are sequences of individual concepts rather than sequences of individuals (see Lewis (1972)). For any attribute of degree $n, \operatorname{val}\left(R_{n}, m / h\right) \in \mathcal{P}\left(\right.$ Concepts $\left.^{n}\right) ; \operatorname{val}\left(R_{n}, m / h\right)$ is the set of $n$-uples of individual concepts to which the attribute $R_{n}$ applies in circumstance $m / h$ according to val. As usual, an attribute $R_{0}$ of degree 0 holds in circumstance $m / h$ according to a denotation assignment $\operatorname{val}$ when $\operatorname{val}\left(R_{n}, m / h\right)$ is the set containing the empty sequence.

The set Val contains a real valuation val $\mathcal{M}$ that assigns to concepts and attributes their actual denotation in each possible circumstance according to model $\mathcal{M}$. Moreover, there corresponds to each agent $a$, moment $m$ and assignment val a particular set $\operatorname{val}(a, m)$ containing all concepts and attributes that the agent $a$ has in mind at that moment according to that assignment. Of course, $\operatorname{val}(a, m)=\varnothing$ when $a \notin$ Agents $\cap$ Individuals $_{m}$. Any non empty set $\operatorname{val}(a, m)$ contains the rigid individual concept $c_{a}$ whose denotation is agent $a$ in any possible circumstance for any denotation assignment. For any agent who thinks or acts has a concept of him or herself. Possible denotation assignments respect the nature of the identity relation and of logical operations on attributes like reflexivization and necessitation. By definition, $<c_{e}^{1}, c_{e}^{2}>\in \operatorname{val}($ Identity,$m / h)$ iff $\operatorname{val}\left(c_{e}^{1}, m / h\right)=\operatorname{val}\left(c_{e}^{2}, m / h\right)$. Two alternative moments $m$ and $m^{\prime}$ are psychologically compatible as regards an agent according to a denotation assignment val (in symbols $m^{\prime} \in$ Compatible $\left._{m}^{a}(\mathrm{val})\right)$ when that agent could then possess according 
to that assignment all the attitudes that he or she has at both moments. The relation of psychological compatibility between moments is reflexive and symmetric for each agent. In order that a moment $m^{\prime}$ be compatible with all the attitudes of an agent $a$ at another moment $m$, both must belong to histories with the same past. Every agent persists in the world. What an agent thinks or attempts at each moment depends on how the world has been up to that moment. The possible causes and effects so to speak of the attitudes and actions of an agent at a moment are limited to those which are possible outcomes of the way the world has been up to that moment. This is why the relation of compatibility with attitudes has to satisfy Belnap's historical relevance condition.

(7) Belief, Knowledge, Desire, Intention, Want, and Granted are functions from Agents $\times$ Moments $\times$ Val into $\mathcal{P}(\mathrm{Val})$ that determine agents' attitudes in model $\mathcal{M}$.

By definition, Belie $f_{m}^{a}(\mathrm{val})$ is the set of possible denotation assignments that are compatible in model $\mathcal{M}$ with the truth of all beliefs that the agent $a$ possesses at the moment $m$ according to val. In particular, Belie $f_{m}^{a}(\mathrm{valM})$ is the set of possible denotation assignments that are compatible with the truth of all beliefs that agent $a$ has at moment $m$ according to model $\mathcal{M}$. Similarly, Desire ${ }_{m}^{a}(\mathrm{val})$ is the set of possible denotation assignments that are compatible in model $\mathcal{M}$ with the realization of all desires that agent $a$ possesses at the moment $m$ according to $\mathrm{val}$. An agent has no attitude at a moment when he or she has no attribute or individual concept in mind at that moment. Thus Belief $f_{m}^{a}(v a l)$ and Desire ${ }_{m}^{a}(v a l)$ are the whole set Val when $\operatorname{val}(a, m)=\varnothing$. Otherwise, they are non empty proper subsets of Val. Agents are competent. Whenever an agent has in mind attributes and concepts, some possible denotation assignments to these senses are compatible with what that agent then believes or desires. Moreover, that agent has then in mind all these senses in compatible assignments. 
If $v^{\prime \prime} l^{\prime \prime} \in$ Belief $_{m}^{a}(v a l) \cup \operatorname{Desire} m_{m}^{a}$ then $\operatorname{val}(a, m) \subseteq \operatorname{val}^{\prime}(a, m)$. Agents can have desires that they do not desire to have. But they cannot have a belief without believing that they have it. The relation of compatibility with the truth of beliefs is then transitive. If $v a l^{\prime} \in$ Belief $_{m}^{a}(v a l)$ and $v a l^{\prime \prime} \in$ Belief $_{m}^{a}\left(v_{a l}^{\prime}\right)$ then $v a l^{\prime \prime} \in$ Belief $_{m}^{a}(v a l)$.

Knowledge represents the cognitive way proper to knowledge; Want and Intention the volitive ways proper to will and intention. Knowledge and Want are functions from Agents $\times$ Moments $\times$ Val into $\mathcal{P}(V a l)$ that restrict respectively Belief and Desire. Agents can have false beliefs but they can only know true propositions. The cognitive mode of knowledge is then reflexive: val $\in$ Knowledge ${ }_{m}^{a}(\mathrm{val})$. Whoever intends something wants that thing. Thus Intention $_{m}^{a}(v a l) \subseteq$ Want $_{m}^{a}($ val $)$. Like the relation of cognitive compatibility corresponding to beliefs, characteristic cognitive and volitive ways of knowledge and intention are transitive. Agents can have desires that they do not desire to have. But they cannot know something without knowing that they know it. And they cannot execute an intention without intending to execute that intention. Thus if $v a l^{\prime} \in$ Knowledge $_{m}^{a}(v a l)$ and $v a l^{\prime \prime} \in$ Belief $_{m}^{a}\left(v l^{\prime}\right)$ then $v a l^{\prime \prime} \in \operatorname{Belief}_{m}^{a}(v a l)$. And similarly for $\operatorname{Intention}_{m}^{a}(v a l)$. For each agent $a$, moment $m$ and valuation val, Granted ${ }_{m}^{a}(v a l)$ is the non empty set of all possible denotation assignments that are compatible with the truth of all propositions that a presupposes at moment $m$ according to val. Granted ${ }_{m}^{a}$ is transitive.

(8) The set Predications is a subset of $\mathcal{P}($ Attributes $\cup$ Concepts $)$ that contains all sets of propositional constituents with which one can make a predication $\mathscr{L}$. Such sets are of the form $\left\{R_{n}, c_{e}^{1}, \ldots, c_{e}^{k}\right\}$; they contain a single attribute $R_{n}$ of degree $n$ and a positive number $k(k \leq n)$ of individual concepts $c_{e}^{1}, \ldots, c_{e}^{k}$ when $n$ is positive. Unlike truth functions, modal, temporal and attitude propositional operations serve to make predications of new modal, temporal, epistemic and volitive attributes. In thinking that it is impossible that God makes mistakes we predicate 
of Him the modal property of infallibility. Whoever thinks that God created the world predicates of Him the past property of having created the world. Whoever thinks that the pope believes that God exists predicates of God the epistemic property of being existent according to the pope. Whoever wishes that God forgives him predicates of God the property that he would prefer God's pardon.

The power set $\mathcal{P}$ Predications is then closed in each model under union, a modal and temporal unary operation * and, for each individual concept $c_{e}$, a unary psychological and praxeological operation $\otimes c_{e}$. For any set $\Gamma \subseteq$ Predications, $\cup^{*} \Gamma$ contains all modal and temporal attributes that one can form with attributes of $\cup \Gamma$. Similarly $\cup \otimes c_{e} \Gamma$ contains epistemic and volitive properties corresponding to beliefs or desires that the agent falling under concept $c_{e}$ could form with attributes of $\cup \Gamma$. As usual, modal and temporal operation ${ }^{*}$ and praxeological operations of the form $\otimes c_{e}$ obey the following postulates: $\Gamma \subseteq{ }^{*} \Gamma$ and ${ }^{*} \Gamma \subseteq \otimes c_{e} \Gamma .{ }^{*}\left(\Gamma_{1} \cup \Gamma_{2}\right)={ }^{*} \Gamma_{1} \cup{ }^{*} \Gamma_{2}$ and ${ }^{* *} \Gamma={ }^{*} \Gamma$. Similarly, $\otimes c_{e}\left(\Gamma_{1} \cup \Gamma_{2}\right)=\otimes c_{e} \Gamma_{1} \cup \otimes c_{e} \Gamma_{2}$ and $\otimes c_{e} \otimes c_{e} \Gamma=\otimes_{c^{e}} \Gamma$. Whoever has in mind an individual concept can attribute attitudes to the individual to which that concept applies. Consequently, when $\cup \Gamma \subseteq \operatorname{val}(a, m)$ and $c_{e} \in \operatorname{val}(a, m), \cup \otimes c_{e} \Gamma \subseteq \operatorname{val}(a, m)$.

(9) $\mathcal{U}$ is a function that associates with each type $\alpha$ the set $\mathcal{U}_{\alpha}$ of all entities that are possible semantic values of formulas of that type in model $\mathcal{M}$. By definition, (i) $U_{\# e}=$ Concepts, (ii) $U_{r}=$ Attributes. (iii) $U_{p} \subseteq \mathcal{P}[$ Predications $] \times($ Circumstances $\rightarrow \mathcal{P}($ Val $))$. (iv) $U_{\bar{\omega}} \subseteq$ $($ Agents $\times$ Times $\times$ Val $) \rightarrow \mathcal{P V a l} . \quad(\mathrm{v}) U_{\theta} \subseteq($ Agents $\times$ Times $) \rightarrow$ $\left.\mathcal{P}\left(U_{p}\right)\right)$ and (vi) $U_{\Sigma} \subseteq($ Agents $\times$ Times $\times U p) \rightarrow \mathcal{P} U_{p}$. The union of all such sets $U_{\alpha}$ is the domain of the possible interpretation $\mathcal{M}$.

$U_{p}$ is the set of first order propositions of model $\mathcal{M}$. When an attribute is predicated of $n$ individuals under concepts in a proposition $P$, the set containing that attribute and these $n$ concepts belongs to the first term $i d_{1} P$ of that proposition. Thus the set of all propositional 
constituents of a proposition $P$ is the union $\cup i d_{1} P$. The second term $i d_{2} P$ of proposition $P$ is the family of all sets of possible denotation assignments that are compatible with its truth in each circumstance. Thus proposition $P$ is true in circumstance $m / h$ according to a possible denotation assignment val iff $v a l \in i d_{2} P(m / h)$.

(10) Goal is a function from Agent $\times$ Time $\times$ Val into $\mathcal{P} U_{p}$ that serves to determine propositional content conditions of agents' intentions in model $\mathcal{M}$. Goal ${ }_{m}^{a}(\mathrm{val})$ is the set of propositions representing objectives that agent $a$ has at moment $m$ according to denotation assignment val. Thus $\bigcup_{\text {val } \in \text { Val }}$ Goal $_{m}^{a}(\mathrm{val})$ contains propositions representing objectives that agent a could have at moment $m$. Goal satisfies the following postulates:

- Any agent intends to carry it out and can express his or her goals. Thus if $\left.P \in \operatorname{Goal}_{m}^{a}(v a l)\right)$ then $\cup i d_{1} P \subseteq \operatorname{val}(a, m)$ and Intention $_{m}^{a}\left(v_{a l}\right)$ $\subseteq i d_{2} P\left(m / h_{m}\right)$.

- Agents have a free will. $P \in$ Goal $_{m}^{a}($ val $)$ only if $P \notin$ Goal $_{m^{\prime}}^{a}(v a l)$ for at least one moment $m^{\prime}$ coinstantaneous with moment $m$.

- Many individual intentions and attempts are personal. An agent can only intend that he or she do something. So when $a \neq b, G_{\text {oal }}^{a}(\mathrm{val})$ $\neq$ Goal $_{m}^{b}(\mathrm{val})$.

- Agents' intentions are directed towards the present or the future. When $P \in \operatorname{Goal}_{m}^{a}(\mathrm{val})$ there is no proposition $Q$ such that $i d_{2} P\left(m^{*} / h\right)$ $=\bigcap i d_{2} Q\left(m^{\prime} / h\right)$ for moments $m^{\prime}$ anterior to $m$.

- Agents always believe that they can reach their objectives. So they do not intend to do things that they believe to be necessary or impossible. When $P \in \operatorname{Goal}_{m}^{a}(\mathrm{val})$ and $\mathrm{val}^{\prime} \in \operatorname{Belief}_{m}^{a}(\mathrm{val})$ for one but not all circumstances $m^{\prime} / h^{\prime}$ coinstantaneous with $m, v a l^{\prime} \in i d_{2} P\left(m^{\prime} / h^{\prime}\right)$.

(11) Reason is a function from Times $\times U_{p} \times V$ al into $\mathcal{P}\left(U_{p}\right)$. The set Reason ( $m, P, \mathrm{val}$ ) contain all propositions that represent reasons why proposition $P$ is true at moment $m$ according to assignment 
val. In my view, any reason for $P$ is a cause of the fact that represents. Causes precede or are simultaneous with their effects. There are natural causes. Some facts are effects of other facts given laws of nature. There are also intensional causes. Some facts turn to be existent because of attitudes or actions of agents. Agents have attitudes and make attempts for practical reasons. They have intentions because they have desires and beliefs about how to satisfy these desires. They act in order to keep previous commitments. Sometimes there is a causal over-determination. They think or do something for different reasons. By definition, causes produce their effect: when a proposition $Q \in \operatorname{Reason}(m, P, v a l)$, val $\in i d_{2} P\left(m / h_{m}\right)$ and val $\in i d_{2} Q\left(m / h_{m}\right)$. Moreover the same causes produce the same effects at alternative moments which are psychologically compatible as regards an agent. Consequently when $Q \in \operatorname{Reason}(m, P, v a l)$, at all moments $m^{\prime} \in$ Compatible $\left._{m}^{a}(\mathrm{val})\right)$ if val $\in i d_{2} Q\left(m^{\prime} / h_{m^{\prime}}\right)$ then val $\in i d_{2} P\left(m^{\prime} / h_{m^{\prime}}\right)$.

(12) Finally, \|\| is a function that associates with each term $A$ of type $\alpha$ and possible context of utterance $c$ the entity $\|A\|_{c}$ of $U_{\alpha}$ that $A$ expresses in that context according to the possible interpretation $\mathcal{M}$.

The evaluation function \|\| satisfies the following clauses:

- For any constant $A$ of $\mathscr{L}$ of type $\alpha\|A\|_{c} \in U_{\alpha}$. Thus if $\mathrm{t}$ is an individual constant, $\|t\|_{c} \in$ Concepts and for any predicate $R_{n}$ of degree $n,\left\|R_{n}\right\|_{c} \in \operatorname{Attributes}(n)$.

- In particular, $\left\|={ }_{2}\right\|_{c}=$ Identity; $\|$ Bel $\|_{c}=$ Belief and $\|$ Des $\|_{c}=$ Desire.

- $\|$ Want $\bar{\omega}_{\bar{\omega}} \|_{c}=$ Want, $\|$ Int $_{\bar{\omega}} \|_{c}=$ Intention, $\left\|K_{\bar{\omega}}\right\|_{c}=$ Knowledge and $\left\|\operatorname{Int}_{\theta}\right\|_{c}(a, m)=$ Goal $_{m}^{a}$.

- $\left\|1_{\bar{\omega}}\right\|_{c}(a, m, v a l)=$ Belief $_{m}^{a}(v a l) \cup D e s i r e e_{m}^{a}(v a l)$ and $\left\|1_{\theta}\right\|_{c}(a, m)=$ $U_{p}$ and $\left\|1_{\Sigma}\right\|_{c}(a, m, P)=\varnothing$.

- $\left\|A_{\theta} \cap B_{\theta}\right\|_{c}(a, m)=\left\|A_{\theta}\right\|_{c}(a, m) \cap\left\|B_{\theta}\right\|_{c}(a, m)$. And similarly for $\cup$.

Manuscrito - Rev. Int. Fil., Campinas, v. 34, n. 1, p. 323-364, jan.-jun. 2011. 
- $\left\|A_{\Sigma} \cup B_{\Sigma}\right\|_{c}(a, m, P)=\left\|A_{\Sigma}\right\|_{c}(a, m, P) \cup\left\|B_{\Sigma}\right\|_{c}(a, m, P)$. And similarly for $\cap$.

- $\left\|A_{\bar{\omega}} \cap B_{\bar{\omega}}\right\|_{c}(a, m, v a l)=\left\|A_{\bar{\omega}}\right\|_{c}(a, m, v a l) \cap\left\|B_{\bar{\omega}}\right\|_{c}(a, m, v a l)$. And similarly for $\cup$.

- $\|$ Past $_{\theta} \|_{c}(a, m)=\left\{P \in U_{p} /\right.$ for some proposition $Q$ and for some moments $m^{\prime}$ anterior to $\left.m, i d_{2} P\left(m^{*} / h\right)=\bigcap i d_{2} Q\left(m^{\prime} / h\right)\right\}$.

- $\|$ Future $_{\theta} \|_{c}(a, m)=\left\{P \in U_{p} /\right.$ for some proposition $Q$ and for some moments $m$ ' posterior to $\left.m, i d_{2} P\left(m^{*} / h\right)=\bigcap i d_{2} Q\left(m^{\prime} / h\right)\right\}$.

- $\left\|\left[A_{\bar{\omega}}, A_{\theta}, A_{\Sigma}, B e l\right]\right\|_{c}$ is the function $h$ from Agent $\times$ Times $\times$ Val into $\mathcal{P} U_{p}$ such that $P \in h(a, m, v a l)$ iff $\left(\left\|A_{\bar{\omega}}\right\|_{c}(a, m, v a l) \cap B e l i e f_{m}^{a}(v a l)\right)$ $\subseteq i d_{2} P\left(m / h_{m}\right), P \in\left\|A_{\theta}\right\|_{c}(a, m), \cup i d_{1}(P) \subseteq \operatorname{val}(a, m)$ and, for all $Q \in$ $\left\|A_{\Sigma}\right\|_{c}(a, m, P), \cup i d_{1}(Q) \subseteq \operatorname{val}(a, m)$ and Belief $f_{m}^{a}($ val $) \cup$ Granted $_{m}^{a}$ $(v a l) \subseteq i d_{2} Q\left(m / h_{m}\right)$. Similarly for $\left\|\left[A_{\mu}, A_{\theta}, A_{\Sigma}, D e s\right]\right\|_{c}$ with Desire $e_{m}^{a}$ (val) instead of Belief $f_{m}^{a}(\mathrm{val})$ and the additional condition that for at least one val $^{\prime} \in$ Belief $_{m}^{a}($ val $\left.)\right)$, val $^{\prime} \notin i d_{2}\|P\|\left(m / h_{m}\right)$.

$-i d_{1}\left\|\left[R_{n} t_{1} \ldots t_{n}\right]\right\|_{c}=\left\{\left\{\left\|R_{n}\right\|_{c},\left\|t_{1}\right\|_{c, \ldots,}\left\|t_{n}\right\|_{c}\right\}\right\}$ and $v a l \in i d_{2} \|\left[R_{n} t_{1}\right.$ $\left.\ldots t_{n}\right] \|_{c}(m / h)$ iff $\left.\left.\left.<\left\|t_{1}\right\|_{c, \ldots},\left\|t_{n}\right\|_{c}\right)\right) \in \operatorname{val}\left(\left\|R_{n}\right\|_{c},(m / h)\right)\right\}$.

- $i d_{1}\left\|\neg A_{p}\right\|_{c}=i d_{1}\left\|A_{p}\right\|_{c}$ and val $\in i d_{2}\left\|\neg A_{p}\right\|_{c}(m / h)$ iff val $\notin$ $i d_{2}\left\|A_{p}\right\|_{c}(m / h)$.

- $i d_{1} \|$ Settled $A_{p}\left\|_{c}={ }^{*} i d_{1}\right\| A_{p} \|_{c}$ and $i d_{2} \|$ Settled $A_{p} \|_{c}(m / h)=$

$\bigcap_{m \in h^{\prime}} i d_{2}\left\|A_{p}\right\|_{c}\left(m / h^{\prime}\right)$.

- $i d_{1} \|$ Actually $A_{p}\left\|_{c}={ }^{*} i d_{1}\right\| A_{p} \|_{c}$ and $i d_{2} \|$ Actually $A_{p} \|_{c}(m / h)=$ $i d_{2}\left\|A_{p}\right\|_{c}\left(m_{c} / h_{c}\right)$.

- $\|$ Truth $_{\Sigma} \|_{c}\left(a, m,\left\|A_{p}\right\|_{c}\right)=\left\{\|\right.$ Actually $\left.A_{p} \|_{c}\right\}$

- $i d_{1}\left\|\square A_{p}\right\|_{c}={ }^{*} i d_{1}\left\|A_{p}\right\|_{c}$ and $i d_{2}\left\|\square A_{p}\right\|_{c}^{\sigma}(m / h)=$

$\bigcap_{m^{\prime} \approx m} \bigcap_{m^{\prime} \in h^{\prime}} i d_{2}\left\|A_{p}\right\|_{c}\left(m^{\prime} / h^{\prime}\right)$. 
- $i d_{1} \|$ Tautological $A_{p}\left\|_{c}={ }^{*} i d_{1}\right\| A_{p} \|_{c}$ and $i d_{2} \|$ Tautological $A_{p} \|_{c}$ $(m / h)=V a l$ when $\left.\bigcap_{m^{\prime} / h^{\prime}} i d_{2}\left\|A_{p}\right\|_{c}\left(m^{\prime} / h^{\prime}\right)\right)=$ Val. Otherwise, $i d_{2} \|$ Tautological $A_{p} \|_{c}(m / h)=\varnothing$.

- $i d_{1}\left\|W i l l A_{p}\right\|_{c}={ }^{*} i d_{1}\left\|A_{p}\right\|_{c}$ and $i d_{2}\left\|W i l l A_{p}\right\|_{c}(m / h)=$ $\bigcup i d_{2}\left\|A_{p}\right\|_{c}\left(m^{\prime} / h\right)$. $m^{\prime}>m$

- $i d_{1}\left\|W a s A_{p}\right\|_{c}={ }^{*} i d_{1}\left\|A_{p}\right\|_{c}$ and $i d_{2}\left\|W a s A_{p}\right\|_{c}(m / h)=$ $\bigcup_{m^{\prime}<m} i d_{2}\left\|A_{p}\right\|_{c}\left(m^{\prime} / h\right)$.

- $i d_{1}\left\|\diamond a A_{p}\right\|_{c}=\otimes_{\|a\|_{c}} i d_{1}\left\|A_{p}\right\|_{c}$ and $v a l \in i d_{2}\left\|\diamond a A_{p}\right\|_{c}(m / h)$ if and only if, for some $m^{\prime} \in$ Compatible $_{m}^{a}(\mathrm{val})$ and for some $h^{\prime}$, val $\in i d_{2}\left\|A_{p}\right\|_{c}\left(m^{\prime} / h^{\prime}\right)$.

- $i d_{1}\left(\left\|B_{p} \wedge C_{p}\right\|_{c}\right)=i d_{1}\left(\left\|B_{p}\right\|_{c}\right) \cup i d_{1}\left(\left\|C_{p}\right\|_{c}\right) ; i d_{2}\left\|B_{p} \wedge C_{p}\right\|_{c}(m / h)=$ $i d_{2}\left\|B_{p}\right\|_{c}(m / h) \cap i d_{2}\left\|C_{p}\right\|_{c}(m / h)$.

- $\left.i d_{1}\left(\| B_{p}\right\} C_{p} \|_{c}\right)=^{*}\left(i d_{1}\left(\left\|B_{p}\right\|_{c}\right) \cup i d_{1}\left(\left\|C_{p}\right\|_{c}\right)\right)$ and $\left.i d_{2} \| B_{p}\right\} C_{p} \|_{c}$ $(m / h)=V a l$ when $i d_{1}\left\|B_{p}\right\|_{c} \supseteq i d_{1}\left\|C_{p}\right\|_{c}$. Otherwise, $\left.i d_{2} \| B_{p}\right\} C_{p} \|_{c}$ $(m / h)=\varnothing$.

- $\left.i d_{1} \|\left[a B e l A_{\bar{\omega}} A_{p}\right)\right]\left\|_{c}=\otimes_{\|a\|_{c}} i d_{1}\right\| A_{p} \|_{c}$ and val $\left.\in i d_{2} \|\left[a B e l A_{\bar{\omega}} A_{p}\right)\right] \|_{c}(m / h)$ iff $\left\|A_{p}\right\|_{c} \in\left\|\left[A_{\bar{\omega}}, 1_{\theta}, 1_{\Sigma}, B e l\right]\right\|_{c}(v a l$ $\left.\left(\|a\|_{c}, m_{c} / h_{c}\right), m, v a l\right)$. And similarly for $\left.\|\left[a D e s A_{\bar{\omega}} A_{p}\right)\right] \|_{c}$ with Des instead of Bel.

- $i d_{1}\left\|\left[\rho B_{p} C_{p}\right]\right\|_{c}=\left(i d_{1}\left\|B_{p}\right\|_{c} \cup i d_{1}\left\|C_{p}\right\|_{c}\right)$ and $v a l \in i d_{2}\left\|\left[\rho B_{p} C_{p}\right]\right\|_{c}$ $(m / h)$ iff $\|$ Actually $C_{p} \|_{c} \in \operatorname{Reason}\left(m,\left\|B_{p}\right\|_{c}\right.$, val $\left.)\right\}$.

- $i d_{1}\left\|A_{\theta} a A_{p}\right\|_{c}=\otimes_{\|a\|_{c}} i d_{1}\left\|A_{p}\right\|_{c}$ and $v a l \in i d_{2}\left\|A_{\theta} a A_{p}\right\|_{c}(m, h)$ iff $\left.\left\|A_{p}\right\|_{c} \in\left\|A_{\theta}\right\|\left(\operatorname{val}\|a\|_{c}\left(m_{c} / h_{c}\right), m\right)\right\}$.

- $i d_{1}\left\|\left(A_{\Sigma} a A_{p}\right)\right\|_{c}$ is $\otimes_{\|a\|_{c}} i d_{1}\left\|A_{p}\right\|_{c}$ and $i d_{2}\left\|\left(A_{\Sigma} a A_{p}\right)\right\|_{c}(m / h)$ is the intersection of all sets $i d_{2} P(m / h)$ for all propositions $P \in\left\|A_{\Sigma}\right\|_{c}\left(\operatorname{val}\left(\|a\|_{c}, m_{c} / h_{c}\right), m,\left\|A_{p}\right\|_{c}\right)$.

- $i d_{1}\left\|\left[>>a A_{p}\right]\right\|_{c}=\otimes_{\|a\|_{c}} i d_{1}\left\|A_{p}\right\|_{c}$ and $v a l \in i d_{2}\left\|\left[>>a A_{p}\right]\right\|_{c}(m / h)$ iff $\left.\cup i d_{1}\left(\left\|A_{p}\right\|_{c}\right) \subseteq \operatorname{val}\left(\left(\operatorname{val}\|a\|_{c}\left(m_{c} / h_{c}\right), m\right)\right)\right)$ and $\operatorname{Granted}_{m}^{a}(\operatorname{val}) \subseteq$ $i d_{2}\left\|A_{p}\right\|_{c}\left(m / h_{m}\right)$ where $a=\operatorname{val}\|a\|_{c}\left(m / h_{m}\right)$. 
- $\left\|\left(A_{M} A_{p}\right)\right\|_{c}=<\left\|A_{p}\right\|_{c},\left\{(a, m, v a l) /\left\|A_{p}\right\|_{c} \in\left\|A_{M}\right\|_{c}(a, m, v a l)\right\}$.

A propositional formula $A_{p}$ of $\mathscr{L}$ is true in a possible circumstance $m / h$ according to a standard model $\mathcal{M}$ when $\left\|A_{p}\right\|$ is true in $m / h$ according to valM. $A_{p}$ is valid (in symbols: $=A_{p}$ ) when it is true in all possible circumstances according to all standard models.

\section{VALID LAWS}

Here is a list of fundamental valid laws of my logic of propositional attitudes. As one can expect, all the instances in language $\mathscr{L}$ of classical axiom schemas of truth functional logic, $S 5$ modal logic for settled truth, historic and universal necessities, Brouwer's modal logic for psychological necessity and branching temporal logic for past and future are valid formulas.

S5 Modal logic for settled truth, historic and logical necessity

$(S 1) \models\left(\right.$ Settled $\left.A_{p} \Rightarrow A_{p}\right)$

$(S 2) \models\left(\operatorname{Settled}\left(A_{p} \Rightarrow B_{p}\right) \Rightarrow\left(\operatorname{Settled} A_{p} \Rightarrow \operatorname{Settled} B_{p}\right)\right)$

$(S 3) \models\left(\neg\right.$ Settled $\neg A_{p} \Rightarrow$ Settled $\neg$ Settled $\left.\neg A_{p}\right)$ and similarly for and

Notice that $\mid \neq$ Settled $A_{p} \Rightarrow \square A_{p}$ and $\mid \neq \square A_{p} \Rightarrow$ Tautological $A_{p}$.

Brouwer's modal logic for psychological necessity

$(\diamond 1)\left|=\left(A_{p} \Rightarrow \diamond a A_{p}\right)(\diamond 2)\right|=\left(\varpi a\left(A_{p} \Rightarrow B_{p}\right) \Rightarrow\left(\varpi a A_{p} \Rightarrow \varpi a B_{p}\right)\right)$

$(\diamond 3)=\left(A_{p} \Rightarrow \varpi a \diamond a A_{p}\right)$

Valid schemas for tautologies

$(T 1) \mid=$ Tautological $A_{p} \Rightarrow \mathbf{a} A_{p}$. However $\mid \models \mathbf{a} A_{p} \Rightarrow$ Tautological $A_{p}$.

(T2) $\mid=$ Tautological $A_{p} \Rightarrow$ TautologicalTautological $A_{p}$

(T3) $=\neg$ Tautological $A_{p} \Rightarrow$ Tautological $\neg$ Tautological $A_{p}$. 
(T4) $=$ Tautological $A_{p} \Rightarrow$ (Tautological $\left(A_{p} \Rightarrow B_{p}\right) \Rightarrow$ Tautological $\left.B_{p}\right)$.

$(T 5) \mid=$ Tautological $B_{p} \Rightarrow$ (Tautological $\left(A_{p} \Rightarrow B_{p}\right) \Rightarrow$ Tautological $\left.A_{p}\right)$.

$\left.(T 6-7) \mid=\left(A_{p}\right\} B_{p}\right) \Rightarrow$ Tautological $\left.\left.\left(A_{p}\right\} B_{p}\right) \mid=\neg\left(A_{p}\right\} B_{p}\right) \Rightarrow$ Tautological $\left.\neg\left(A_{p}\right\} B_{p}\right)$.

\section{Valid schemas for propositional identity}

$$
\begin{aligned}
& \quad(I 1)=\left(\left[R_{n} t_{1} \ldots t_{n}\right]=\left[R_{n}^{k} d_{1} \ldots d_{n}\right]\right) \Leftrightarrow\left(( ( R _ { n } = { } ^ { \wedge } R _ { n } ^ { k } ) ) \wedge \left(\left(t_{1}=\right.\right.\right. \\
& \left.\left.\left.\hat{\left.d_{1}\right)} \vee \ldots \vee\left(t_{1}=\hat{d}_{n}\right)\right) \wedge \ldots \wedge\left(t_{n}=\hat{\imath}_{1}\right) \vee \ldots \vee\left(t_{n}={ }^{\prime} d_{n}\right)\right)\right) \wedge \ldots \wedge \\
& \left.\left.\left(\left(d_{1}=\hat{t}_{1}\right) \vee \ldots \vee\left(d_{1}=\hat{t}_{n}\right)\right) \wedge \ldots \wedge\left(d_{n}=\hat{t}_{1}\right) \vee \ldots \vee\left(d_{n}=\hat{t}_{n}\right)\right)\right) \wedge \\
& \text { Tautological }\left(\left(R_{n} t_{1} \ldots t_{n}\right) \Leftrightarrow\left(R_{n}^{k} d_{1} \ldots d_{n}\right)\right) \\
& \quad(I 2) \models A_{p}=A_{p} \\
& \quad(I 3) \models\left(A_{p}=B_{p}\right) \Rightarrow\left(C \Rightarrow C^{*}\right) \text { where } C^{*} \text { and } C \text { are propositional }
\end{aligned}
$$
formulas which differ at most by the fact that an occurrence of $B_{p}$ in $C^{*}$ replaces an occurrence of $A_{p}$ in $C$.

$$
\begin{aligned}
& (I 4)=\left(A_{p}=B_{p}\right) \Rightarrow \text { Tautological }\left(A_{p}=B_{p}\right) \\
& (I 5)=\neg\left(A_{p}=B_{p}\right) \Rightarrow \text { Tautological } \neg\left(A_{p}=B_{p}\right)
\end{aligned}
$$

\section{Valid schemas for propositional composition}

$$
\begin{aligned}
& \left.(C 0) \models\left(\left[R_{n} t_{1}, \ldots, t_{n}\right]\right\} A_{p}\right) \Rightarrow\left(A_{p}=\left[R_{n} t_{1}, \ldots, t_{n}\right]\right) \\
& \left.(C 1) \models A_{p}\right\} A_{p} \\
& \left.\left.\left.(C 2) \models\left(A_{p}\right\} B_{p}\right) \Rightarrow\left(\left(B_{p}\right\} C_{p}\right) \Rightarrow\left(A_{p}\right\} C p\right)\right) \\
& \left.(C 3) \models\left(A_{p} \wedge B_{p}\right)\right\} A_{p} \\
& \left.(C 4) \models\left(A_{p} \wedge B_{p}\right)\right\} B_{p} \\
& \left.\left.\left.(C 5) \models\left(\left(C_{p}\right\} A_{p}\right) \wedge\left(C_{p}\right\} B_{p}\right)\right) \Rightarrow C_{p}\right\}\left(A_{p} \wedge B_{p}\right) \\
& \left.(C 6) \models A_{p}\right\}\left\{\neg A_{p}\right. \\
& \left.(C 7) \models \square A_{p}\right\}\left\{\text { Tautological } A_{p}\right. \text { and similarly for Will,Was, }
\end{aligned}
$$

Actually and other modal and temporal connectives.

$$
\begin{aligned}
& \left.(C 8) \models\left(A_{p}\right\} B_{p}\right) \equiv \square\left(A_{p} \wedge B_{p}\right) \\
& \left.(C 9) \models \square A_{p}\right\} A_{p}
\end{aligned}
$$


$\left.(C 10) \models\left[\operatorname{aHas}\left(A_{M} A_{p}\right)\right]\right\} \square A_{p}$

$\left.(C 11) \models \square \neg A_{p}\right\}\left\{\square A_{p}\right.$ and similarly for $\left[\operatorname{aHas}\left(A_{M} A_{p}\right)\right]$

$\left.(C 12) \models \square\left(A_{p} \wedge B_{p}\right)\right\}\left\{\left(\square A_{p} \wedge \square B_{p}\right)\right.$ and similarly for $\left.\left[a B e l A_{\bar{\omega}} A_{p}\right)\right]$ and $\left.\left[a \operatorname{Des} A_{\bar{\omega}} A_{p}\right)\right]$.

$\left.(C 13) \mid=\square \square A_{p}\right\}\left\{\square A_{p}\right.$ and similarly for $\left.\left[a \operatorname{Bel} A_{\bar{\omega}} A_{p}\right)\right]$ and $\left.\left[a \operatorname{Des} A_{\bar{\omega}} A_{p}\right)\right]$.

$\left.\left.(C 14)=\left[a \operatorname{Bel} A_{\bar{\omega}} A_{p}\right)\right]\right\}\left\{\left[a \operatorname{Des} A_{\bar{\omega}} A_{p}\right)\right]$

\section{Branching time logic}

$(T L 1) \mid=\left(\right.$ Will-always $\left(A_{p} \Rightarrow B_{p}\right) \Rightarrow\left(\right.$ Will-always $A_{p} \Rightarrow$ Willalways $\left.\left.B_{p}\right)\right)$ where $W i l l-$ always $A_{p}={ }_{\text {def }} \neg W i l l \neg A_{p}$.

$(T L 2) \mid=\left(\right.$ Was-always $\left(A_{p} \Rightarrow B_{p}\right) \Rightarrow\left(\right.$ Was-always $A_{p} \Rightarrow$ Wasalways $\left.\left.B_{p}\right)\right)$

$(T L 3)=\left(A_{p} \Rightarrow\right.$ Was - alwaysWill $\left.A_{p}\right)$

$(T L 4)=\left(A_{p} \Rightarrow\right.$ Will - alwaysWas $\left.A_{p}\right)$

$(T L 7)=\left(\right.$ Was $A_{p} \Rightarrow$ Will - alwaysWas $\left.A_{p}\right)$

$(T L 8)=\left(W_{i l l} A_{p} \Rightarrow\right.$ Will $-\operatorname{always}\left(W i l l A_{p} \vee A_{p} \vee W a s A_{p}\right)$

$(T L 9)=\left(\right.$ Was $_{p} \Rightarrow$ Was $-\operatorname{always}\left(\right.$ Will $\left.A_{p} \vee A_{p} \vee W a s A_{p}\right)$

\section{Historic modality with time}

$(M T 1) \mid=\left(\right.$ Was $\left(\left(A_{p} \wedge\right.\right.$ Will - always $\left.B_{p}\right) \wedge$ Was - always $\neg\left(B_{p} \wedge\right.$ $\left.\left.\diamond C_{p}\right)\right) \Rightarrow\left(\left(\right.\right.$ Will - always $D_{p} \wedge W a s C_{p} \Rightarrow$ Was $\left(A_{p} \wedge\left(C_{p} \vee W a s C_{p}\right) \wedge\right.$ Will - always $\left(C_{p} \Rightarrow\right.$ Will - always $\left.\left.\left.D_{p}\right)\right)\right)$

$(M T 2) \models\left(\right.$ Was-always $\left(A_{p} \wedge\right.$ Was-always $\neg\left(B_{p} \wedge \diamond C_{p}\right) \wedge W i l l\left(B_{p} \wedge\right.$ $\left.\left.A_{p} \wedge \diamond D_{p}\right)\right) \wedge W a s\left(\left(E_{p} \wedge\right.\right.$ Will - always $\left.\left.B_{p}\right)\right) \Rightarrow\left(\left(\right.\right.$ Will - always $Q_{p} \Rightarrow$ Was $\left(E_{p} \wedge\right.$ Will - always $\left(C_{p} \Rightarrow\right.$ Will - always $\left(D_{p} \Rightarrow\right.$ Will - always $\left.\left.\left.\left.Q_{p}\right)\right)\right)\right)^{6}$

${ }^{6}$ Axioms (MT1-2) are A. Zanardo [1985]'s axioms of local correspondence. 


\section{Indexical Temporal logic}

$$
\begin{aligned}
& (\text { IT1 })=\left(\text { Actually }\left(\text { Actually } A_{p} \Rightarrow A_{p}\right)\right) \\
& \left(\text { IT2) }=\left(\text { Actually } A_{p} \Rightarrow \text { AlwaysActually } A_{p}\right)\right. \\
& \left(\text { IT3) }=\left(\text { Actually } A_{p} \Rightarrow \text { SettledActually } A_{p}\right)\right. \\
& \left(\text { IT4) }=\left(\text { Actually }\left(A_{p} \wedge B_{p}\right) \Leftrightarrow\left(\text { Actually } A_{p} \wedge \text { Actually } B_{p}\right)\right)\right. \\
& \left(\text { IT5) }=\left(\text { ActuallyActually } A_{p} \Leftrightarrow \text { Actually } A_{p}\right)\right.
\end{aligned}
$$

\section{Valid schemas for belief}

$(B 1)=\left(\right.$ Bela $_{p} \wedge$ Bela $\left.B_{p}\right) \Rightarrow \operatorname{Bela}\left(A_{p} \wedge B_{p}\right)$

(B2) $=$ Tautological $A_{p} \Rightarrow \neg$ Bela $\neg A_{p}$

$(B 3) \mid=$ Tautological $A_{p} \Rightarrow\left(\left(\left(\right.\right.\right.$ Bela $\left.\left.B_{p}\right) \wedge\left(B_{p}\right\} A_{p}\right) \Rightarrow$ BelaTautological $\left.A_{p}\right)$

$(B 4)=$ Bela $_{p} \Rightarrow\left(\left(A_{p} \mapsto B_{p}\right) \Rightarrow\left(\right.\right.$ Bela $\left.\left.B_{p}\right)\right)$

$(B 5)=$ Bela $_{p} \Leftrightarrow\left(\right.$ BelaBela $\left.A_{p}\right)$

$(B 6)=$ Satisfied $\left[\right.$ Bela $\left.A_{p}\right] \Leftrightarrow\left(\left[\right.\right.$ Bela $\left.A_{p}\right] \wedge$ Actually $\left.A_{p}\right)$

Notice that beliefs are detachable: $\models \operatorname{Bela} A_{p} \Rightarrow\left(\left(\operatorname{Bela}\left(A_{p} \Rightarrow\right.\right.\right.$ $\left.\left.\left.B_{p}\right)\right) \Rightarrow\left(\operatorname{Bela} B_{p}\right)\right)$.

But agents do not believe all universal necessities. $\quad \neq \square A_{p} \Rightarrow$ BelaA $A_{p}$

They can even believe necessarily false propositions. $\mid \neq \neg A_{p} \Rightarrow$ $\operatorname{Bela} \neg A_{p}$.

Inconsistent agents are paraconsistent. $\mid \neq \neg A_{p} \Rightarrow\left(\right.$ Bela $_{p} \Rightarrow$ $\left.\operatorname{Bela} B_{p}\right)$.

Agents are also not logically omniscient. $\quad \not \neq$ Tautological $A_{p} \Rightarrow$ $\operatorname{Bela} A_{p}$.

In particular, agents do not make all tautological inferences. $\forall\left(\right.$ Tautological $\left.\left(A_{p} \Rightarrow B_{p}\right)\right) \Rightarrow\left(\right.$ Bela $\left.\left.A_{p} \Rightarrow \operatorname{Bela} B_{p}\right)\right)$

For conclusions of tautological inferences can contain new predications. $\mid=\left(\right.$ Tautological $\left.\left.\left.\left(A_{p} \Rightarrow B_{p}\right)\right) \Rightarrow\left(A_{p}\right\} B_{p}\right)\right)$.

However agents are minimally consistent; they cannot believe strongly incompatible propositions. $\mid=$ Tautological $\left(A_{p} \Rightarrow B_{p}\right) \Rightarrow$ 
$\left(\right.$ Bel $A_{p} \longrightarrow \neg$ Bela $\left.\neg B_{p}\right)$

All the classical Boolean laws of idempotence, commutativity, associativity and distributivity are valid laws of propositional identity:

So $=\operatorname{Bela} A_{p}=\operatorname{Bela}\left(A_{p} \wedge A_{p}\right) ; \mid=\operatorname{Bela}\left(A_{p} \wedge B_{p}\right)=\operatorname{Bela}\left(B_{p} \wedge A_{p}\right)$ and $=\operatorname{Bela}\left(A_{p} \wedge B_{p}\right)=\operatorname{Bela}\left(\backsim A_{p} \wedge \boldsymbol{\square} B_{p}\right)$.

The classical laws of reduction are also valid: $\models \neg \neg A_{p}=A_{p}$ and $=$ BelaBela $A_{p}=$ Bela $A_{p}$. Unlike hyperintensional logic, predicative logic does not require that identical propositions be intensionally isomorphic. The order of predication does not always affect truth conditions. Similarly, the order and number of applications of propositional operations does not always affect the logical form. Clearly, $=\operatorname{Bela}\left(A_{p} \Leftrightarrow B_{p}\right)=\operatorname{Bela}\left(B_{p} \Leftrightarrow A_{p}\right)$. Intensional isomorphism is too strong a criterion of propositional identity.

However, propositional identity requires more than the co-entailment advocated in the logic of relevance. As M. Dunn pointed out, it is unfortunate that $A_{p}$ and $\left(A_{p} \wedge\left(A_{p} \vee B_{p}\right)\right)$ co-entail each other. For most formulas of such forms are not synonymous. Co-entailment is not sufficient for synonymy because it allows for the introduction of new sense. $\forall A_{p} \mapsto\left(A_{p} \wedge\left(A_{p} \vee B_{p}\right)\right)$.

For $\mid \models \operatorname{Bela} A_{p} \mapsto \operatorname{Bela}\left(A_{p} \wedge\left(A_{p} \vee B_{p}\right)\right.$ in my logic.

\section{Valid schemas for desire}

$(D 1) \models\left(D_{e s a} A_{p} \wedge \operatorname{Desa}_{p}\right) \Rightarrow \operatorname{Desa}\left(A_{p} \wedge B_{p}\right)$. But the converse is not valid.

$$
\begin{aligned}
& (D 2) \models \text { Tautological } A_{p} \Rightarrow \neg\left(\text { Desa }_{p} \vee \text { Desa } \neg R A_{p}\right) \\
& \left.\left.(\text { D3 })=\text { Desa }_{p} \Rightarrow\left(\left(\left(A_{p} \mapsto B_{p}\right) \wedge \neg \text { Tautological } A_{p}\right)\right) \Rightarrow\left(\text { DesaB }_{p}\right)\right)\right) \\
& (D 4)=\text { Desa }_{p} \Rightarrow \text { Bela } \neg \text { Tautological } A_{p} \\
& (D 5)=\text { Satisfied }\left[\text { Desa } A_{p}\right] \Leftrightarrow\left(\left[\text { Desa }_{p}\right] \wedge \text { Actually } A_{p}\right)
\end{aligned}
$$

Notice that unlike belief, desire is not closed under strong implication. $\forall\left(A_{p} \mapsto B_{p}\right) \Rightarrow\left(\right.$ Desa $A_{p} \Rightarrow$ Desa $\left.B_{p}\right)$. For any desire contains a preference. Thus agents cannot desire tautological things (Axiom D2). 
$\models A_{p} \mapsto\left(A_{p} \Rightarrow A_{p}\right)$. But $\mid \models \operatorname{Desa} A_{p} \Rightarrow \operatorname{Desa}\left(A_{p} \Rightarrow A_{p}\right)$.

Unlike beliefs, desires are not detachable. $\mid \neq D e s a A_{p} \Rightarrow\left(\left(\right.\right.$ Bela $\mathbf{\square}\left(A_{p}\right.$ $\left.\left.\Rightarrow B_{p}\right)\right) \Rightarrow\left(\right.$ Desa $\left.\left.B_{p}\right)\right)$.

Agents can desire things that they believe to be impossible. $\forall$ Bela $B_{p} \Rightarrow \neg$ Desa $A_{p}$.

However $\mid=$ Tautological $\left(A_{p} \Rightarrow B_{p}\right) \Rightarrow\left(\right.$ Desa $A_{p} \in \neg$ Desa $\left.\neg B_{p}\right)$.

\section{Valid schemas for propositional attitudes}

$=\left[\operatorname{aHas}\left(\left[\left(A_{\bar{\omega}}, A_{\theta}, A_{\Sigma}, B e l\right] A_{p}\right)\right] \Leftrightarrow\left(\left[\operatorname{aHas}\left(\left[A_{\bar{\omega}}\right]\right.\right.\right.\right.$ Belief $\left.\left.A_{p}\right)\right] \wedge\left(A_{\theta} a\right.$ $\left.\left.A_{p}\right) \wedge\left[\operatorname{Bela} A_{\Sigma} a A_{p}\right] \wedge\left(>>a A_{\Sigma} a A_{p}\right)\right)$

$=\left[\operatorname{aHas}\left(\left[\left(A_{\bar{\omega}}, A_{\theta}, A_{\Sigma}, \operatorname{Des}\right] A_{p}\right)\right] \Leftrightarrow\left(\left[\operatorname{aHas}\left(\left[A_{\bar{\omega}}\right]\right.\right.\right.\right.$ Desire $\left.\left.A_{p}\right)\right] \wedge\left(A_{\theta} a\right.$ $\left.A_{p}\right) \wedge\left[\right.$ Bela $\left.A_{\Sigma} a A_{p}\right] \wedge\left(>>a A_{\Sigma} a A_{p}\right) \wedge$ Bela $\neg$ Tautological $\left.A_{p}\right)$

$=\left[\operatorname{aHas}\left(\left(A_{M} A_{p}\right] \Rightarrow \operatorname{Settled}\left[\operatorname{aHas}\left(\left(A_{M} A_{p}\right)\right]=\left(\left[A_{\varsigma}\right] A_{M} A_{p}\right)\right.\right.\right.$ $\left(A_{M} A_{p}\right)$

$=\operatorname{Satisfied}\left(A_{M} a A_{p}\right) \Rightarrow\left(\neg \varnothing\left(A_{M}\right) \wedge\right.$ Actually $\left.A_{p}\right)$

$=\left(\neg \varnothing\left(A_{M}\right) \wedge \neg A_{M}\left(\right.\right.$ Want $\left.\left._{\bar{\omega}}\right) \wedge\left[\operatorname{aHas}\left(A_{M} A_{p}\right)\right]\right) \Rightarrow\left(\operatorname{Satisfied}\left(A_{M} a\right.\right.$ $\left.A_{p}\right) \Leftrightarrow$ Actually $\left.A_{p}\right)$

$=\left(\neg \varnothing\left(A_{M}\right) \wedge A_{M}\left(\right.\right.$ Want $\left.\left._{\bar{\omega}}\right)\right) \Rightarrow\left(\operatorname{Satisfied}\left(A_{M} a A_{p}\right) \Leftrightarrow[\rho(\right.$ Actually $\left.\left.A_{p}\right)\left[\operatorname{aHas}\left(A_{M} A_{p}\right)\right]\right)$

Valid schemas for knowledge

$(K 1)=\left[K a A_{p}\right] \Rightarrow\left(A_{p} \wedge\left[\right.\right.$ BelaA $\left.A_{p}\right]$

$(K 2)=\left[K a A_{p}\right] \Rightarrow\left[K a K a A_{p}\right]$

$(K 3)=$ Tautological $A_{p} \Rightarrow\left(\left[\operatorname{aHas}\left(A_{M} A_{p}\right)\right] \Rightarrow\left[K a A_{p}\right]\right)$. But $\forall$ Tautological $A_{p} \Rightarrow K a A_{p}$.

$(K 4)\left|=K a A_{p} \Rightarrow\left(\left(A_{p} \mapsto B_{p}\right) \Rightarrow\left(K a B_{p}\right)\right)\right| \neq\left(\right.$ Tautological $\left(A_{p} \Rightarrow\right.$ $\left.\left.\left.B_{p}\right)\right) \Rightarrow\left(K a A_{p} \Rightarrow K a B_{p}\right)\right)$ 


\section{Valid schemas for intention}

$$
\begin{aligned}
& (I 1)=\text { Int }_{\theta} a A_{p} \Rightarrow \neg\left(A_{p}=\text { WasB }_{p}\right) \\
& \left(\text { I2) }=\text { Satisfied }\left(\text { IntaA } A_{p}\right) \Leftrightarrow\left[\rho\left(\text { Actually } A_{p}\right)\left[\text { IntaA } A_{p}\right]\right]\right. \\
& \left(\text { I3) }=\left[\text { Inta }_{p}\right] \Rightarrow\left(\left(\text { Bela } \diamond A_{p} \wedge \text { Bela } \neg \square A_{p}\right) \wedge \text { Desa } A_{p}\right)\right)
\end{aligned}
$$

\section{PRINCIPLES OF REVISION OF ATTITUDES}

Agents keep many attitudes during an interval of time. Whenever they acquire a new propositional attitude they then lose old attitudes that are incompatible with the new attitude and they acquire others whose nature can be determined with the conceptual apparatus of my logic. Minimally rational agents could not have simultaneously attitudes of certain forms at certain moments. One can introduce psychological incompatibility in my ideography as follows: $\left(A_{M} A_{p}\right)><_{a}$ $\left(B_{M} B_{p}\right)=_{\text {def }} \neg \diamond\left(\left[\operatorname{aHas}\left(A_{M} A_{p}\right)\right] \wedge\left[\operatorname{aHas}\left(B_{M} B_{p}\right)\right]\right)$. Certain incompatible attitudes are such that no agent could possess them at any moment. In that case, $\left.=\left[\operatorname{aHas}\left(A_{M} A_{p}\right)\right] \mapsto \neg\left[\operatorname{aHas}\left(B_{M} B_{p}\right)\right]\right)$.

My first principle of update is a principle of revision: any agent who acquires a new attitude loses eo ipso all previous attitudes that are incompatible with that new attitude. There are many reasons of incompatibility between attitudes. Propositional attitudes can be incompatible because they contain incompatible beliefs or desires or incompatible cognitive or volitive ways, propositional content or preparatory conditions. For example agents lose beliefs that they discover to be false and they revoke previous intentions that they discover to be impossible to execute. My logic gives a general account for psychological incompatibility. My second principle of update is an expansion principle: Whenever an agent acquires a new propositional attitude $M(P)$ he or she acquires eo ipso many other new attitudes $M^{\prime}(P)$ with the same propositional content $P$ whose modes $M^{\prime}$ can be determined given propositional content conditions that $P$ then satisfies and other 
attitudes that that agent has at that moment about $P$. Let me give a few examples. Suppose that an agent who sees a lot of heavy low clouds in the sky gets to believe that it will soon rain. Because that new belief is directed towards the future, he or she then foresees that it will rain. For the mode of prevision is obtained from that of belief by adding the special propositional content condition that the represented fact is future with respect to the moment of the attitude. Suppose that that new belief puts then the agent in a state of expectation (special cognitive way), he or she then also expects rain. Suppose moreover that that agent previously hoped and still desires that it would not soon rain. Because hope is a desire whose satisfaction is then possible according to the agent (special preparatory condition), the agent then loses the previous hope and feels moreover a disappointment. Whoever is disappointed with a fact desires its inexistence while believing (special preparatory conditions) that the fact exists and that he or she previously believed that it would not exist.

The expansion principle that I have just stated generates new attitudes having the same propositional content but a new mode, my second expansion principle generates new attitudes having the same mode but a new propositional content. That second expansion principle is based on the fact that most components of psychological modes $M$ are compatible with conjunction. Suppose that an agent $a$ acquiring a new attitude $M(P)$ at a moment also possesses at that moment another attitude $M(Q)$ with propositional content $Q$. Then he or she also acquires the new attitude $M(P \wedge Q)$ whose content is the conjunction of these propositions in case both attitudes $M(P)$ and $M(Q)$ strongly commit that agent to the new attitude $M(P \wedge Q)$ that is to say when $\left\{\left(A_{M} A_{p}\right),\left(A_{M} B_{p}\right)\right\} \triangleright a\left(C_{M} C_{p}\right)$. This is always the case when $M$ is a primitive psychological mode. For the categories of cognition and volition are compatible with conjunction. Whoever believes (or desires) two things believes (or desires) both. Moreover many but 
not all cognitive and volitive ways and preparatory and propositional content conditions are compatible with conjunction. So are for example the special volitive way of pleasures, the propositional content condition of previsions and the preparatory condition of satisfactions. Suppose that an agent who is satisfied to win a competition is also satisfied with the received price. Then that agent is satisfied with both facts. For the mode of satisfaction is obtained from that of desire by adding the preparatory condition that the desired fact exists. Whoever is pleased with something feels a satisfied desire whose satisfaction puts him or her in a state of pleasure. Clearly no agent can be pleased with one fact and with another without being pleased with both. Similarly two previsions strongly commit the agent to foreseeing their conjunction. For if two propositions are future with respect to a moment so is their conjunction. Notice that the volitive mode of agreements and the propositional content condition of approvals are not compatible with conjunction. Sometimes it is good to do one thing and good to do another thing but it is not good to do both. So one can approve one thing and approve another thing without approving both. A cognitive or volitive way $A_{\bar{\omega}}$ is compatible with conjunction when $=\left(\left[\operatorname{aHas}\left(\left[A_{\bar{\omega}}\right] A_{M} A_{p}\right)\right] \wedge\left[\operatorname{aHas}\left(\left[A_{\bar{\omega}}\right] A_{M} B_{p}\right)\right]\right) \Rightarrow$ $\left[\operatorname{aHas}\left(\left[A_{\bar{\omega}}\right] A_{M}\left(A_{p} \wedge B_{p}\right)\right]\right)$. A propositional content condition $A_{\theta}$ is compatible with conjunction when $=\left(\left(A_{\theta} a A_{p}\right) \wedge\left(A_{\theta} a B_{p}\right)\right) \Rightarrow A_{\theta} a\left(A_{p} \wedge\right.$ $\left.\left.B_{p}\right)\right)$. A preparatory condition $A_{\Sigma}$ is compatible with conjunction when $=\left(\left(A_{\Sigma} a A_{p}\right) \wedge\left(A_{\Sigma} a B_{p}\right)\right) \Rightarrow\left(A_{\Sigma} a\left(A_{p} \wedge B_{p}\right)\right.$. On the basis of previous considerations, one can formulate as follows my update theory for attitudes where $\left[\operatorname{aacquires}\left(A_{M} A_{p}\right)\right]$ and $\left[\operatorname{akeeps}\left(A_{M} A_{p}\right)\right]$ are new formulas.

The revision principle: $=\left(\left[\right.\right.$ aacquires $\left.\left(A_{M} A_{p}\right)\right] \wedge\left(A_{M} A_{p}\right)><_{a}$ $\left.\left(B_{M} B_{p}\right)\right) \Rightarrow \neg\left[\operatorname{akeeps}\left(A_{M} A_{p}\right)\right]$

First expansion principles: $=\left(\left[\right.\right.$ aacquires $\left.\left.\left(A_{M} A_{p}\right)\right] \wedge\left(A_{\theta} a A_{p}\right)\right) \Rightarrow$ $\left[\operatorname{aacquires}\left(\left[A_{\theta}\right] A_{M} A_{p}\right)\right]$; 
$=\left(\left[\operatorname{aacquires}\left(A_{M} A_{p}\right)\right] \wedge\left[\right.\right.$ Bela $\left.\left.A_{\bar{\omega}} A_{p}\right]\right) \Rightarrow\left[\operatorname{aacquires}\left(\left[A_{\theta}\right] A_{M} A_{p}\right)\right]$ when $B e l$ is part of $A_{M}$ and $=\left(\left[\right.\right.$ aacquires $\left.\left(A_{M} A_{p}\right)\right] \wedge\left[\right.$ Desa $\left.\left.A_{\bar{\omega}} A_{p}\right]\right) \Rightarrow$ [aacquires $\left.\left(\left[A_{\theta}\right] A_{M} A_{p}\right)\right]$ when Des is part of $A_{M}$.

$=\left(\left[\operatorname{aacquires}\left(A_{M} A_{p}\right)\right] \wedge\left[\operatorname{Bela}_{\Sigma} a A_{p}\right] \wedge\left[>>a A_{\Sigma} a A_{p}\right]\right) \Rightarrow$ [aacquires $\left.\left(\left[A_{\Sigma}\right] A_{M} A_{p}\right)\right]$

Second expansion principles: $\mid=\left(\left[\right.\right.$ aacquires $\left.\left(A_{M} A_{p}\right)\right] \wedge\left[\operatorname{aHas}\left(A_{M}\right.\right.$ $\left.\left.\left.B_{p}\right)\right]\right) \Rightarrow\left[\operatorname{aHas}\left(A_{M}\left(A_{p} \wedge B_{p}\right)\right]\right)$ when $A_{M}=$ Bel or Des.

Suppose that $M(P) \in N e w$ Attitudes $_{m}^{a}(\mathrm{val})$. If $P \in \theta(a, m)$ then $[\theta] M(P) \in$ NewAttitudes ${ }_{m}^{a}(v a l)$. For $=\left[\right.$ aHas $\left.\left(\left[A_{\theta}\right] A_{M} A_{p}\right)\right] \Leftrightarrow([a H a s$ $\left.\left(A_{M} A_{p}\right)\right] \wedge\left(A_{\theta} a A_{p}\right)$. If moreover $P$ is true in $m$ according to all possible denotation assignments of $\bar{\omega}(a, m, v a l)$ then $[\bar{\omega}] M(P) \in$ NewAttitudes $s_{m}^{a}$ $($ val $)$. Indeed $\models\left[\operatorname{aHas}\left(\left[A_{\bar{\omega}}\right] A_{M} A_{p}\right)\right] \Leftrightarrow\left(\left[\operatorname{aHas}\left(A_{M} A_{p}\right)\right] \wedge\left[\operatorname{Bela} A_{\bar{\omega}} A_{p}\right]\right)$ when Bel is part of $A_{M}$ and $=\left[\operatorname{aHas}\left(\left[A_{\bar{\omega}}\right] A_{M} A_{p}\right)\right] \Leftrightarrow\left(\left[\operatorname{aHas}\left(A_{M} A_{p}\right)\right] \wedge\right.$ $\left.\left[\operatorname{Desa} A_{\bar{\omega}} A_{p}\right]\right)$ when Des is part of $A_{M}$. Finally, if every proposition $Q \in \Sigma(a, m, P)$ is true at moment $m$ according to all possible denotation assignments of Belief $f_{m}^{a}(\mathrm{val}) \cap$ Granted $_{m}^{a}(\mathrm{val})$ then $[\Sigma] M(P) \in$ NewAttitudes ${ }_{m}^{a}($ val $)$. For $=\left[\operatorname{aHas}\left(\left[A_{\Sigma}\right] A_{M} A_{p}\right)\right] \Leftrightarrow\left(\left[\operatorname{aHas}\left(A_{M} A_{p}\right)\right] \wedge\right.$ $\left[\right.$ Bela $\left.A_{\Sigma} a A_{p}\right] \wedge\left[>>a A_{\Sigma} a A_{p}\right]$.

\section{APPENDIX: SEMANTIC TABLEAUX}

My lexical analysis of terms for attitudes explains comparative strength between psychological modes. Here are two semantic tableaux showing relations of comparative strength between cognitive and volitive modes. The initial node of the first tableau is the term "belief" which names the primitive cognitive mode; the initial node of the second is the term "desire" that names the primitive volitive mode. Any immediate successor of a term names a stronger mode obtained by applying one or more operations whose nature is indicating by symbols in the branch between the two terms. See my next book Speech Acts in Dialogue for more explanation. 


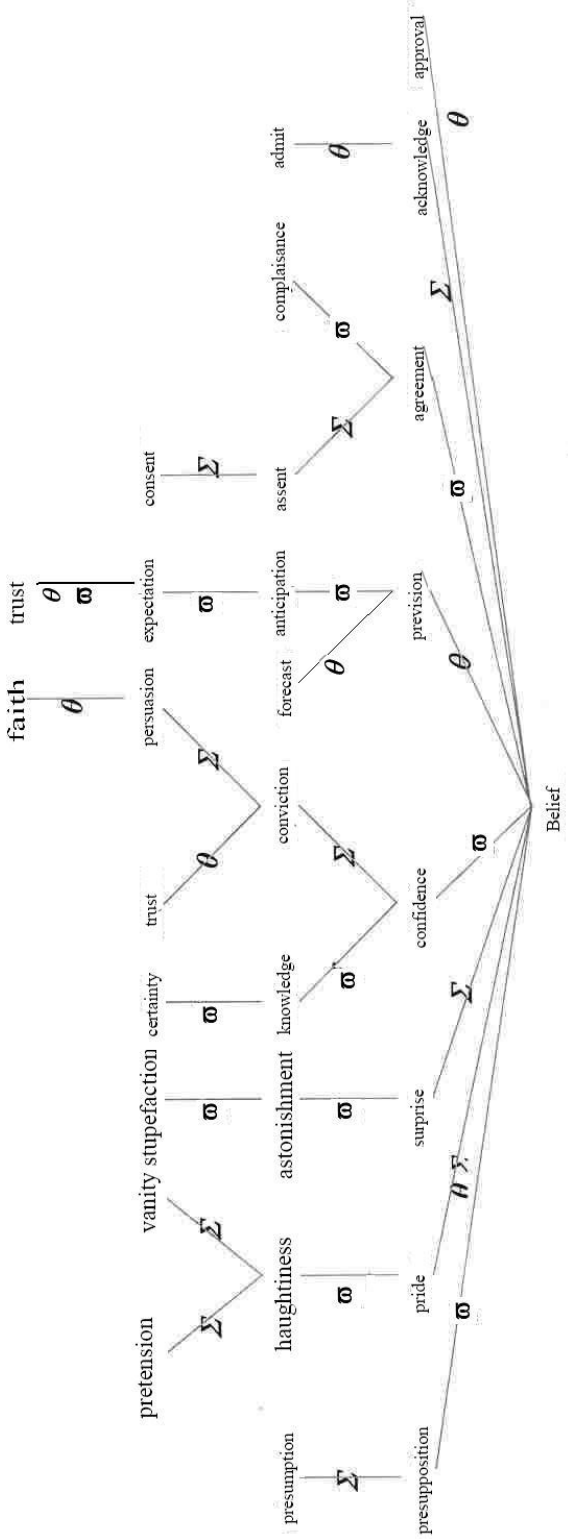




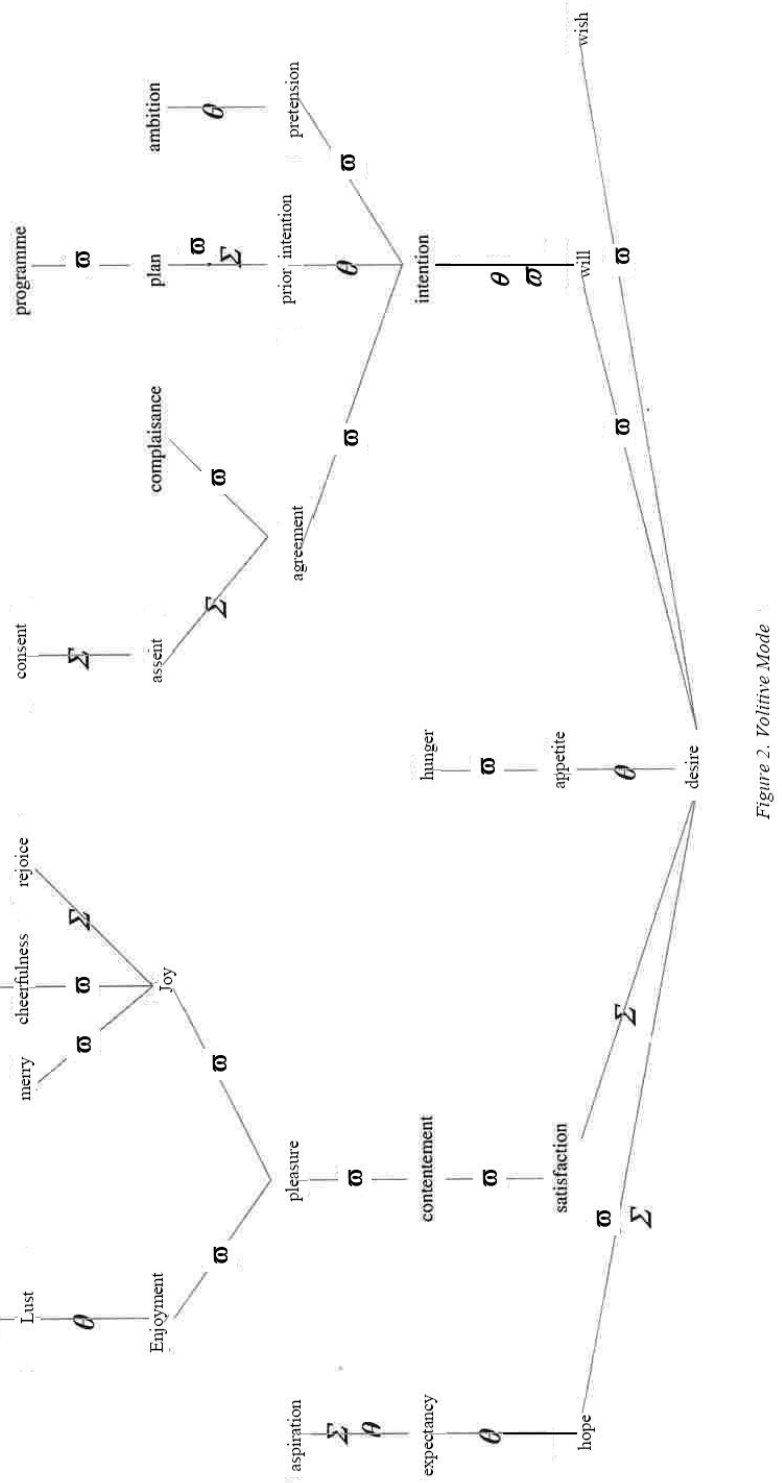

Manuscrito - Rev. Int. Fil., Campinas, v. 34, n. 1, p. 323-364, jan.-jun. 2011. 


\section{REFERENCES}

BEALER, G. Quality and Concept. Oxford University Press, 1982.

BELNAP, N., PERLOFF, M. and XU, M. Facing the Future: Agents and Choices in Our Indeterminist World. Oxford University Press, 2001.

CHERNIAK, C. Minimal Rationality. MIT Press, 1986.

da COSTA, N., BÉZIAU, J.-Y., and BUENO, O. "On the Usefulness of Paraconsistent Logic" in D. Vanderveken (ed.) Logic, Thought and Action. Springer, 2005.

HINTIKKA, J. "Semantics for Propositional attitudes" in L. Linsky (ed) Reference and Modality. Oxford U.P., 1971.

LEWIS, D. "General Semantics." In D. Davidson G. Harman (eds) Semantics of Natural Language. Reidel, 1972.

PRIOR, A. N. Past, Present and Future. Oxford, Clarendon Press, 1967.

SEARLE, J. and D. VANDERVEKEN, D. Foundations of Illocutionary Logic. Cambridge University Press, 1985.

VANDERVEKEN, D. "A General Logic of Propositional Attitudes" in Cédrémont C. et al. Dialogues, Logic and Other Strange Things. Vol 7, series Tributes, College Publications, p. 449-83, 2008.

hansson et al. Logic, Ethics and All that Jazz, Essays in Honour of Jordan Howard Sobel. Uppsala Philosophical Studies, n. 57, 2009 . 